\title{
Integrated methodological frameworks for modeling agent- based advanced supply chain planning systems: A systematic literature review
}

Luis Antonio Santa-Eulalia ${ }^{1}$, Georgina Halladjian ${ }^{1}$, Sophie D'Amours ${ }^{2}$, Jean-Marc Frayret ${ }^{3}$

${ }^{1}$ Téluq - Université du Québec à Montréal, ${ }^{2}$ Université Laval, ${ }^{3}$ École Polytechnique de Montréal

$(C A N A D A)$

leulalia@,teluq.uqam.ca; halladjian.georgina@yahoo.ca; Sophie.Damours@gmc.ulaval.ca; Jean-

Marc.Frayret@polymtl.ca

Received January 2011

Accepted September 2011

\section{Abstract:}

Purpose: The objective of this paper is to provide a systematic literature review of recent developments in methodological frameworks for the modelling and simulation of agent-based advanced supply chain planning systems.

Design/methodology/approach: A systematic literature review is provided to identify, select and make an analysis and a critical summary of all suitable studies in the area. It is organized into two blocks: the first one covers agent-based supply chain planning systems in general terms, while the second one specializes the previous search to identify those works explicitly containing methodological aspects.

Findings: Among sixty suitable manuscripts identified in the primary literature search, only seven explicitly considered the methodological aspects. In addition, we noted that, in general, the notion of advanced supply chain planning is not considered unambiguously, that the social and individual aspects of the agent society are not taken into account in a clear manner in several studies and that a significant part of the works are of a theoretical nature, with few real-scale 
industrial applications. An integrated framework covering all phases of the modelling and simulation process is still lacking in the literature visited.

Research limitations/implications: The main research limitations are related to the period covered (last four years), the selected scientific databases, the selected language (i.e. English) and the use of only one assessment framework for the descriptive evaluation part.

Practical implications: The identification of recent works in the domain and discussion concerning their limitations can help pave the way for new and innovative researches towards a complete methodological framework for agentbased advanced supply chain planning systems.

Originality/value: As there are no recent state-of-the-art reviews in the domain of methodological frameworks for agent-based supply chain planning, this paper contributes to systematizing and consolidating what has been done in recent years and uncovers interesting research gaps for future studies in this emerging field.

Keywords: supply chain management, advanced supply chain planning systems, agentbased modelling and simulation, methodological frameworks

\section{Introduction}

The Supply Chain Management (SCM) paradigm is widely discussed today in virtually all industry sectors. A supply chain (SC) is a network of autonomous or semi-autonomous companies responsible for raw materials extraction, transformation into intermediary and finished products, as well as distribution and delivery to final consumers (Lee \& Billington, 1993). These systems encompass several characteristics that render them quite intricate, according to the complexity's theory.

In order to cope with this complexity, modelling and simulation techniques are frequently used to understand these systems and to propose the best way to exploit them. For example, scientists and practitioners model and simulate supply chains to deal with problems related to: dynamic scheduling and shop floor job assignment, planning and scheduling integration problems, supply chain coordination problems, supply chain dynamics problems (Lee \& Kim, 2008), 
information sharing, supply chain control structures, intelligent behaviour of supply chain members, evaluation of supply chain push and pull strategies, autonomy of supply chain partners and problem-solving algorithms and methods, among several other possibilities described in the literature.

In an attempt to model and simulate these problems, many techniques have emerged since the 1950's. Santa-Eulalia, D'Amours, Frayret and Azevedo (2009a) reviewed the state of the art of modelling and simulation techniques for capturing the complexity of supply chain systems. In this work, fourteen different modelling and simulation approaches were identified and organized into a novel taxonomy. One of the most pre-eminent categories identified is called multi-agent systems. Derived from Artificial Intelligence, this technique provides an innovative way to model and treat supply chain management problems.

To extend this previous study, the objective of this paper is to review the literature related to agent-based systems for SCM. To do so, a new taxonomy classifying different methodological frameworks for modelling SCM problems was created. This taxonomy identifies that several dissimilar methods have been employed to represent agents in an SC since the 1990's, as will be explained in the next subsection. The present work focuses on a specific category of this taxonomy which models "agent-based systems" to perform "advanced SC planning". These agentbased systems are defined here as d-APS (distributed Advanced Planning and Scheduling systems), as proposed by Santa-Eulalia, Frayret and D'Amours (2008).

These systems represent an emergent domain, arising from the convergence of two fields of research. The first field deals with APS systems, proposing a centralized and hierarchical perspective of supply chain planning, generally treating a single company's supply chain operations planning system. The second field concerns agent-based manufacturing technology, which entails the development of distributed software systems to support the management of production and distribution systems. APS systems employing agent technology (hereafter d-APS) propose mechanisms that overcome some of the limitations of traditional APS systems mainly related to: i) the inability to create sophisticated simulation scenarios (i.e. APS only proposes what-if analysis of part of the SC); and ii) the limitation in modelling distributed contexts to capture important business phenomena like negotiation and cooperation (Santa-Eulalia et al., 2008).

In the domain of d-APS systems there is an important research gap (Govindu \& Chinnam, 2010; Santa-Eulalia, Aït-Kadi, D'Amours, Frayret \& Lemieux, 2011; Santa-Eulalia, 2009), which limits researchers in fully taking advantage of 
simulations: in this area, simulations are normally developed and implemented directly from pre-stated requirements with little explicit focus on system analysis, specification, design and implementation in an integrated manner. Several works exist to specify and design agent-based simulation for SCM, but few approaches exist that integrate the entire development process. Moreover, the methodological aspects are not usually exploited explicitly. This results in a typical problem in agent-based systems, i.e. the engineering divergence phenomenon (Michel, Gouaïch \& Ferber, 2003), where the conceptual model is incomplete or inadequate in different ways, consequently yielding outputs that are different from the stakeholder's real requirements for simulation.

In this sense, this paper aims to organize and identify the main recent advances in the domain of methodological frameworks. This will contribute to systematize and consolidate what has been done in recent years and also uncover possible interesting research gaps for future studies in this emerging field. In order to do so, a systematic approach is employed so as to guarantee a rigorous, transparent and reproducible procedure aiming to identify, select and make an analysis and a critical summary of all suitable studies dealing with this promising research area.

This paper is organized as follows. First, Section 2 presents two taxonomies organizing the modelling and simulation techniques for SC, with special attention given to agent-based methodologies. Section 3 puts forward the research methodology employed. Section 4 presents the main results of this study and finally, Section 5 outlines some discussions and final remarks.

\section{Supply Chain Modelling and Simulation}

"Modelling and simulation is the use of models, including emulators, prototypes, simulators, and stimulators, either statically or over time, to develop data as a basis for making managerial or technical decisions. The terms "modelling" and "simulation" are often used interchangeably" (DoD, 1998).

Many efforts for modelling and simulating SC systems have been made since the 1950's. Santa-Eulalia et al. (2009a) proposed a taxonomy to organize the literature review on modelling and simulation techniques for supply chains. It represents how we understand the domain and it is divided as follows:

- SC Simulation: represents essentially descriptive modelling techniques, in which the main objective is to create models for describing the system itself. Modellers develop these kinds of models to understand the modelled 
system and/or to compare the performance of different systems. Several techniques were surveyed, including System Dynamics (Kim \& Oh, 2005), Monte Carlo Simulation (Biwer, Griffith \& Cooney, 2005), Discrete-Event Simulation (Van Der Vorst, Tromp, \& Van der Zee, 2005), Combined Discrete-Continuous techniques (Lee \& Liu, 2002) and Supply Chain Games (Van Horne \& Marier, 2005).

- SC Optimization: refers to normative models, i.e. models that suggest how the system should or ought to be. Modellers develop these kinds of models mainly to discover the ideal situation concerning the modelled system (optimal behaviours). Examples of the studied techniques include MultiEchelon Inventory Systems ( $\mathrm{Ng} \&$ Piplani, 2003), Classic SC Optimization (Ouhimmou, D'Amours, Beauregard, Aït-Kadi \& Chauhand, 2008), and Statistical Analysis-Based and Non-Parametric Optimization (Chen, Yang \& Yen, 2007). There is also a set of Statistical Analysis-Based techniques, which are divided into Combined Optimization - Monte Carlo (Beaudoin, Lebel \& Frayret, 2007), Business Games (Moyaux, Chaib-draa, \& D'Amours, 2007), Stochastic Programming-based (Kazemi, Aït-Kadi \& Nourelfath, 2010) and Fuzzy Logic-Based techniques (Ganga, 2010).

- Basic Hybrid Approaches: it is interesting to note that in between Simulation techniques and Optimization approaches, there is a basic hybrid approach called Simulation Optimization. This technique combines characteristics of both SC Simulation (i.e. descriptive models) and SC Optimization (i.e. normative models), and it is being widely discussed in the literature.

- Artificial Intelligence: descriptive and/or normative models, used to create models that try to mimic systems including human behaviour for supply chain management. Modellers employ these models to describe the system (most of the applications available in the literature), or for optimizing it, or both (like the system proposed by Frayret, D'Amours, Rousseau, Harvey \& Gaudreault, 2007). This approach is explained in detail in the next subsection.

In addition, it is important to mention that there are other techniques in the literature, but they are not very common in the surveyed works. Some examples are spreadsheet simulations (Kleijnen, 2005; Chwif, Barretto \& Saliby, 2002), mental simulations (Escalas, 2004; Penker \& Wytrzens, 2005), case base reasoning (Kwon, Im \& Lee, 2005), and traditional Queuing models (Amouzegar \& 
Moshirvaziri, 2006). For more details about these techniques, the reader is referred to Santa-Eulalia et al. (2009a).

\subsection{Multi-Agent Systems for Supply Chain Planning}

From the artificial intelligence field a set of techniques fall under the umbrella of multi-agent-based systems. They model systems that are composed of distributed interacting intelligent entities, called agents, which solve problems that are difficult or simply impractical for a monolithic model to solve. In this context, diverse agents work together and interact with one another to accomplish some tasks. All of the agents use their abilities and knowledge to strengthen the problem-solving capacity of the whole planning system. Due to this distinctiveness, such a system is of great utility in helping solve problems based on multiple methods and that have multiple perspectives (Jarras \& Chaib-draa, 2002).

Multi-agent systems employ mechanisms from distributed artificial intelligence, distributed computing, social network theory, cognitive science, and operational research (Tweedale, 2007; Samuelson, 2005). Examples of these mechanisms include autonomy, pro-activeness and social ability, for example. The social capability is quite interesting in this domain; examples of these abilities include cooperation, coordination and negotiation.

In this context, software agents in SCM generally embed one or more techniques from SC Optimization and SC Simulation to support operations planning or simulation. However, agents usually go further by also embedding negotiation protocols (Forget, D'Amours, Frayret \& Gaudreault, 2008; Dudek \& Stadtler, 2005) or learning algorithms (Carvalho \& Custodio, 2005; Emerson \& Piramuthu, 2004) to address other issues, such as coordination in distributed and complex contexts.

Agent-based approaches for SCM are not new. Since the early 1990's, several developments have targeted the context of distributed decision-making across the supply chain using agent technology. For example, the pioneering work of Fox, Barbuceanu, Gani and Beck (1993), followed by others like Parunak (1998), Swaminathan, Smith and Sadeh (1998), Strader, Lin Tan and Shaw (1998) and Montreuil, Frayret and D'Amours (2000), just to mention a few, have led to significant advances in the area. Nevertheless, the notion of APS systems is generally not treated explicitly. In other words, these works do not clearly address the integration of advanced planning functions with the notion of agents. Basically, APS systems address various functions of supply chain management, including procurement, production, distribution and sales, at the strategic, tactical and 
operational planning levels (Frayret et al., 2007; Stadtler, 2005). These systems stand for a quantitative model-driven perspective on the use of IT in supporting SCM to exploit advanced analysis and supply chain optimization methods.

More recently, agents embedding APS tools and procedures appear to consider these issues more explicitly (Santa-Eulalia et al., 2008). Defined here as d-APS, these systems model the supply chain as a set of semi-autonomous and collaborative entities acting together to coordinate their decentralized plans. The use of agent technology extends traditional APS in order to tackle negotiation and complex coordination issues. In this sense, d-APS systems may provide more modelling functionalities, hence permitting capture of a higher level of complexity in comparison with classic APS systems.

Another interesting advantage of d-APS systems is related to simulation. Agents are largely used for simulation since they naturally model the simultaneous operations of multiple agents in an attempt to re-create and predict the actions of complex phenomena. Thus, simulating actions and interactions of autonomous individuals in a supply chain and with the possibility of assessing their effects on the system as a whole is one interesting property of this system.

To conceive, implement and use d-APS systems, a set of modelling frameworks has been proposed in the literature, as discussed in the next sub-section.

\subsection{Modelling Frameworks for Agent-Based Advanced Supply Chain Planning}

A set of frameworks or methodological approaches can be employed for modelling a simulation environment, varying from traditional development approaches to specific agent-oriented supply chain planning approaches. Figure 1 organizes our literature review of the main approaches that could be useful for modelling a d-APS system. This tree-classification schema adapts and extends the categorization of Bussmann, Jennings and Wooldridge (2004). 


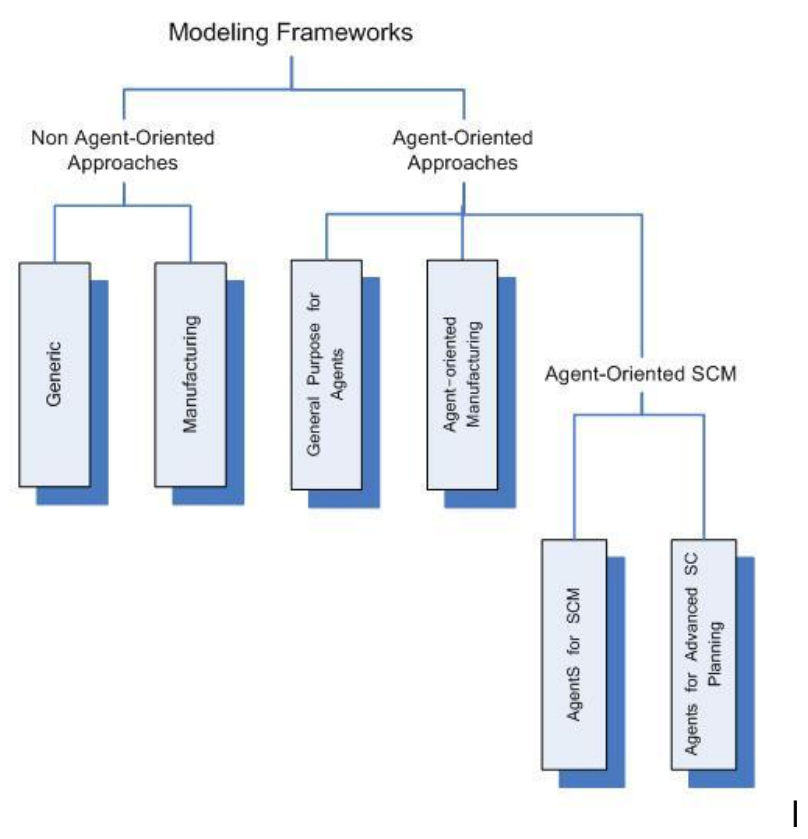

Figure 1. Modelling approaches for agent-based advanced supply chain planning

The following categories are proposed:

- Non Agent-oriented Approaches: refers to modelling paradigms that can be used to model diverse systems, including agent-based systems, without explicitly considering agents' societies. Examples of this category include Generic Approaches such as Data-oriented Approaches (e.g. Jackson, 1975 apud Bussmann et al., 2004), Structural Approaches (e.g. DeMarco, 1978 apud Bussmann et al., 2004) and Object-oriented Approach (e.g. Chatfield, Harrison \& Hayya, 2006). A set of Manufacturing-oriented approaches also exists, with modelling frameworks that vary from modelling formalisms (e.g. SADT/IDEF - Structured Analysis and Design Technique/Integrated Computer Aided Manufacturing Definition - or Petri-Nets approaches) to complete modelling architectures (Vernadat, 1996) (e.g., CIMOSA Computer Integrated Manufacturing Open System Architecture) derived from the field of Enterprise Integration.

- Agent-oriented Approaches: Conventional methodologies have proven unsuitable for engineering agent-based systems (Karageorgos \& Mehandjiev, 2004; Monostori, Vancza \& Kumara, 2006). In this sense, Agent-oriented Approaches (Brugali \& Sycara, 2000) explicitly take into consideration the notion of agent. At this level, two generic classes exist: General Purpose for Agents [e.g. Tropos (Giorgini, Kolp, Mylopoulos \& Pistore, 2003), Prometheus (Padgham \& Winikoff, 2002), MaSE (Wood \& 
DeLoach, 2000), Gaia (Wooldridge, Jennings \& Kinny, 2000), MASCoMoMAS (Iglesias, González \& Velasco, 1998)], which were developed for creating agent-based systems by explicitly incorporating concepts such as autonomy, reactivity, proactivity, and sociability; and Agent-oriented Manufacturing, which provides more explicit guidelines for the identification of agents in production control, but not necessarily dedicated to supply chain problems (e.g. Nishioka, 2004; Bussmann et al., 2004; Parunak, Baker \& Clark, 2001). Although these kinds of approaches are interesting for creating simulation models for our proposed domain, they are not dedicated to the SCM context.

Derived from the Agent-oriented Approaches, a set of techniques appears to explicitly create agents for SCM activities. Named Agent-oriented SCM approaches, this category can be divided into:

- Agents for SCM: Agents are dedicated to supply chain management but are not specialized in the advanced planning domain. Examples of relevant projects in this domain are Labarthe, Espinasse, Ferrarini and Montreuil (2007), Chatfield, Hayya and Harrison (2007), Van der Zee and Van der Vorst (2005), Cavalieri, Cesarotti and Introna (2003), MaMA-S (Galland, Grimaud, Beaune \& Campagne, 2003; Galland, 2001), NetMAN (Montreuil et al., 2000), ISCM (Fox, Barbuceanu \& Teigen, 2000; Fox et al., 1993), MCRA (Ulieru, Norrie, Kremer \& Shen, 2000; Wu, Cobzaru, Ulieru \& Norrie, 2000), CASA/ICAS (Shen \& Norrie, 1999), DASCh (Parunak, 1998; Parunak \& VanderBok, 1998), Strader et al. (1998) and MAIS-Swarm (Lin, Tan \& Shaw, 1998). A detailed and recent comparative discussion about agentbased systems for supply chain management can be found in Monteiro et al. (2008).

- Agents for Advanced SC Planning: derived from Agent-oriented SCM approaches, they explicitly mention the use of optimization procedures or finite capacity planning models when performing supply chain planning. The following projects can be classified as being examples of this category: Santa-Eulalia, D'Amours and Frayret (2010), Egri and Vancza (2005), SNS (Baumgaertel \& John, 2003), Lendermann, Gan and McGinnis (2001), Gjerdrum, Shah and Papageorgiou (2001), MASCOT (Sadeh, Hildum, Kjenstad \& Tseng, 1999), ANTS (Sauter, Parunak \& Goic, 1999) and Swaminathan et al. (1998). 
This work focuses on the last category of the proposed taxonomy. Special attention is given to the methodological aspects of these frameworks, as explained in the next subsection.

\subsection{Methodological Aspects of the Modelling Frameworks}

One important element of these modelling frameworks refers to the methodological aspect. In the software engineering domain, it is known that methodological aspects are quite important, but they are rarely taken into consideration in a clear way in the studied area.

These methodological aspects include procedures and steps for developing a system. For example, a traditional way of developing a system from a software engineering point of view is called the waterfall approach (Pfleeger \& Atlee, 2006), where a set of stages are depicted as cascading from one to another. These stages are analysis, specification, design, implementation, integration and maintenance. Derived from software engineering, specific approaches for agent-based software engineering have appeared more recently (Dam \& Winikoff, 2004). For example, MaSE (Wood \& DeLoach, 2000) which was originally inspired from object-oriented approaches now proposes a complete lifecycle methodology, consisting of seven iterative steps, divided into the initial system analysis and the design. An example of a recent work employing an "Agents for SCM" approach with methodological concern is Govindu and Chinnam (2010). It proposes a method for the analysis and design of multi-agent supply chain systems by integrating the Gaia methodology and the Supply Chain Operations Reference (SCOR) model. Specific works dealing with the methodological aspects will be discussed in Section 4.

Now it is possible to position the present work in relation to the concerned literature. This paper focuses on new developments in the "Agents for Advanced SC Planning" area, with major attention to methodological aspects. As will be discussed later, this area is emerging fast and several interesting research gaps still exist.

Before presenting the main results in Section 4, the next subsection summarizes the research methodology employed in this work.

\section{Methodology}

This section presents the general organization of a systematic review of the domain of "methodological frameworks for modelling d-APS systems". A systematic review is a review following a rigorous, transparent and reproducible procedure aiming to 
identify, select and make an analysis and a critical summary of all suitable studies that deal with a clearly defined question (Becheikh, 2005). Its origin was in medical science, but it can be adapted to different domains. For example, it has recently been used in software engineering and management science.

Based on Becheikh (2005) and Kitchenham et al. (2009), the following phases were defined for the present work:

- Problem formulation: this study consists of a systematic literature review concerning scientific papers and technical reports published between 2007 and 2010 on the selected topic, i.e. on methodological frameworks for agent-based advanced supply chain systems. The last four years were covered to identify only recent advances in the field, as a previous literature review on the domain was provided by Santa-Eulalia (2009) covering the period from 1993 to 2007 . The main research questions addressed by the present study are:

Q1: How many works related to Agent-based Supply Chain Planning systems and their methodological aspects have there been in the past four years?

Q2: What research topics do they address (e.g. planning, scheduling, control, supply, distribution, etc.)?

Q3: How many papers explicitly employ methodological aspects (see subsection 2.3) in their work?

Q4: Do the frameworks explicitly address the APS functions and modules?

Q5: Are social and individual aspects of their agents explicitly considered?

Q6: What are identified as the main limitations of these studies?

Q7: What are the required research advances in the domain?

Q8: Which methodological aspects are covered and which are not in the literature?

- Search strategy: the search was performed in digital works only and in the English-speaking literature. The inclusion criteria comprised i) scientific peer-reviewed articles, published in a peer-reviewed journal or conference or ii) technical reports, from well-established research groups, companies or 
professional societies. The databases employed were Academic Search Premier, Business Source Premier, Google Scholar, ABI-Inform, Proquest and SCOPUS. The final result of this stage was a list of potential articles that had to be analyzed.

- Selection and evaluation of the articles: Figure 2 schematizes this process. The primary literature search (step 1) yielded 60 papers. Of these, 26 were excluded since they did not focus on agent-based systems for advanced SC planning (d-APS, as defined previously), and one was eliminated because the reference was found, but not the full paper. A search from the reference lists of relevant studies led to eight additional studies, which were included in the review process in step 2 . In addition, two references already known by the authors. But not spotted by the primary search, were included manually. From the 34 publications that reached step 2, 27 were eliminated because they did not present specific methodologies for modelling d-APS systems, and seven were further evaluated in step 3. Step 2 produced a comparative table of all agent-based systems for SC planning and step 3 produced a specialized table on modelling frameworks for d-APS systems.

- Finalization: information extraction and organization, as well as findings statement, implications, and recommendations (also for steps 2 and 3).

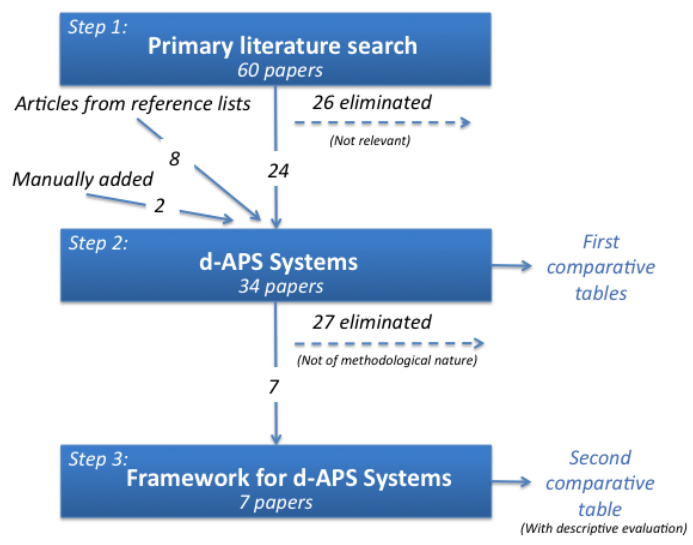

Figure 2. Papers search process

It is important to explain the difference between step 2 and step 3. First, papers are compared in step 2 (d-APS systems) using a general description of each work. On the other hand, a specific descriptive evaluation is performed at step 3 (Frameworks for d-APS Systems) as this work is primarily concerned with the methodological aspects of the papers. 
Diverse approaches from different disciplines exist for evaluating frameworks of software engineering methodologies. Together with the evaluation of general aspects, the Karageorgos and Mehandjiev (2004) approach was employed, inducing a descriptive evaluation method for the specific aspects of agent-based methodologies. This method includes arguing for or against certain characteristics of the evaluated framework without actually applying it, which is useful for discovering some weaknesses in the method, e.g. when desirable features are not supported. It comprises four different conceptually linked views: concepts, models, processes and pragmatics. The framework is summarized in Table 1.

\begin{tabular}{|c|c|}
\hline View & Aspect \\
\hline $\begin{array}{l}\text { Concepts: } \\
\text { concentrates } \\
\text { on which } \\
\text { modelling } \\
\text { concepts are } \\
\text { used. }\end{array}$ & $\begin{array}{l}\text { Concept definition: refers to the restrictive premise concerning the agent-based } \\
\text { architecture and type/class of agents that can be produced using the } \\
\text { methodology. Methodologies can be classified as being open (no consideration for } \\
\text { a particular agent architecture), bounded (consideration for specific architectures, } \\
\text { such as BDI - beliefs, desires and intentions) or limited (highly bounded). It is } \\
\text { preferable for a method to be open. } \\
\text { Design in scope: considers whether a methodology includes steps and guidelines } \\
\text { for the engineering lifecycle. It can be true or false. } \\
\text { Heuristics support: considers whether the methodology provides a formal } \\
\text { support for applying heuristics guidelines and tips for engineering a system. This } \\
\text { formal support can be, in extreme cases, used to provide automation of the } \\
\text { engineering process. It can be true or false. }\end{array}$ \\
\hline $\begin{array}{l}\text { Models: } \\
\text { denotes the } \\
\text { models used } \\
\text { to represent } \\
\text { different } \\
\text { parts of the } \\
\text { system. }\end{array}$ & $\begin{array}{l}\text { Organization settings: concerns whether organization settings (e.g. agents' } \\
\text { roles) are explicitly considered as design constructs. Can be true or false. } \\
\text { Collective behaviour: considers whether the approach includes first-class } \\
\text { modelling constructs to explicitly represent collective agent behaviour or not. Can } \\
\text { be true or false. } \\
\text { Non-functional aspect: regards whether non-functional aspects are explicitly } \\
\text { considered or not. Can be true or false. }\end{array}$ \\
\hline $\begin{array}{l}\text { Processes: } \\
\text { concentrates } \\
\text { on steps that } \\
\text { are executed } \\
\text { to construct } \\
\text { the model. }\end{array}$ & $\begin{array}{l}\text { Design perspective: refers to the perspective from which the methodology is } \\
\text { used. Can be top-down, bottom-up, or both. } \\
\text { Support for reuse: considers whether the methodology supports the use of } \\
\text { previous knowledge. It can be, for example, guidelines for creating, storing and } \\
\text { reusing knowledge. Can be true or false. } \\
\text { Design automation: concerns whether there are formal underpinnings enabling } \\
\text { automation to a certain extent, and which steps could be carried out by a software } \\
\text { tool. Can be true or false. }\end{array}$ \\
\hline $\begin{array}{l}\text { Pragmatics: } \\
\text { evaluates } \\
\text { how practical } \\
\text { the method } \\
\text { is for } \\
\text { engineering } \\
\text { real-world } \\
\text { agent } \\
\text { systems. }\end{array}$ & $\begin{array}{l}\text { Generality: evaluates whether the methodology is based on restrictive premises } \\
\text { concerning the environment and the application domain. Can be characterized as } \\
\text { high (a generic method), medium (there are considerable restrictions, but the } \\
\text { methodology is still wide) or low (applied for specific domains). High generality } \\
\text { results in lower design complexity since it is easier to apply it to diverse domains. } \\
\text { Abstractability: considers whether there is support to enable work at different } \\
\text { levels of abstraction, which is considered by the authors as one of the main } \\
\text { factors affecting design complexity. Can be true or false. } \\
\text { Tool support: concerns whether the approach provides tools supporting the } \\
\text { realization of the method, e.g. agent-based toolkits, or CASE tools. Can be true or } \\
\text { false. }\end{array}$ \\
\hline
\end{tabular}

Table 1. Summarizing the Karageorgos and Mehandjiev's (2004) framework

The next section presents the main results of the systematic research. 


\section{Results}

According to the research objectives stated in Section 1 and the research strategy defined in the last section, the research results are organized in two blocks. First, a general search (step 2) was performed covering works dealing with supply chain planning using agent-based approaches, i.e. the last category of the taxonomy described in subsection 2.2. Afterwards, in the second block the previous search was specialized in order to identify those works explicitly containing methodological aspects for modelling agent-based systems (step 3). These two research blocks are explained in the next two subsections.

\subsection{Agent-Based Supply Chain Planning}

34 papers dealing with d-APS systems were selected for a general comparative study. In order to evaluate these manuscripts, some criteria were defined, according to the research questions listed in Section 3.

First of all, the papers studied were classified depending on the supply chain problem treated. Diverse problems were studied, ranging from SC planning, scheduling, collaboration to lot-sizing.

The second criterion indicated whether the work was applied or not. Papers can be theoretical $(T)$, applied $(A)$, or both (TA). Applied papers employ theoretical developments in real cases by providing proof-of-concepts cases, for example. To complement this discussion, the industry sector mentioned in each applied work was also surveyed. For our concerns, it is important to know whether these new advances are reaching the industry or if they are mostly of a laboratorial nature.

Next, it was identified whether specific implementation toolkits that enable individuals to develop agent-based applications, such as NetLogo, Swarm, Repast, AnyLogic, Maillorca, JADE and others, were employed. This helped to identify if modelling toolkits were associated to any methodological development.

Another important criterion employed refers to the methodological aspects of the frameworks. As the main objective of this work is to treat this aspect, it was verified whether they were explicitly considered. Papers are identified as "Yes" when they put forward the methodological aspects (in this case, the kind of contribution they provide is indicated), as "Some" when only a few elements are considered, or "NI" (i.e. not identified) when it was not possible to detect this criterion for the studied work. 
The notion of APS being clearly treated in the paper was also verified, such as when the authors noticeably identify a set of modules/applications/functionalities/agents for planning and scheduling supply chains. These elements can be at different decision levels (strategic, tactical, operational, control), for different parts of the supply chain (procurement, production, distribution, sales), from the source of raw material to final consumption and return (Stadtler, 2005). Again, the notation "Yes", "Some" and "NI" was employed. This allowed us to identify whether a complete analysis of APS systems was conducted, or if the planning and scheduling approaches were treated partially for specific/dedicated problems.

Finally, two additional criteria related to agents' society were surveyed. The first one refers to social aspects, which are associated with how the society is organized (for example, using autonomous, federated, or hierarchical societies - Shen, Norrie $\&$ Barthès, 2001) and what the agent's relationships are. Also, social aspects can be related to social protocols, i.e. a set of rules governing connections between agents, defining syntactic, semantics and approaches for synchronizing interactions. The second agent-based criterion refers to individual aspects of the society. They stand for different individual roles that agents can play within the society, such as planning and scheduling, controlling, learning, knowledge management, interfacing, and so forth. Sometimes individual aspects comprise internal agent architectures. The objective in analyzing social and individual aspects is to identify if the agent paradigm is really employed, or if it is employed arbitrarily or partially. Again, the notation "Yes", "Some" and "NI" was used.

The next four tables (Table 2, Table 3, Table 4, and Table 5) summarize the main findings of this first research bloc according to a chronological sequence.

\begin{tabular}{|l|l|}
\hline Authors & Andreev et al. (2007) \\
\hline Approach/Project & Adaptive Planning Toolset \\
\hline Contribution & An architecture for performing an adaptive SC planning \\
\hline SC Problem & SC Planning \\
\hline Theoretical or Applied & TA \\
\hline Application Sector & $\begin{array}{l}\text { Airport logistics, factory planning, laundry scheduling and } \\
\text { pharmaceutical logistics }\end{array}$ \\
\hline Specific Implementation Toolkit & NI \\
\hline Methodological approach & NI \\
\hline APS Modules & NI \\
\hline Social Agent Organization & NI \\
\hline Individual Agent Organization & NI \\
\hline Authors & Andrews, Benisch, Sardinha \& Sadeh (2007) \\
\hline Approach/Project & NI \\
\hline Contribution & Inspection of games from one bracket of the 2006 TAC (Trade Agent \\
Competition) semi-finals in order to isolate behavioural features that \\
distinguished top performing agents in this bracket
\end{tabular}




\begin{tabular}{|c|c|}
\hline Individual Agent Organization & NI \\
\hline Authors & Chen \& Wei (2007) \\
\hline Approach/Project & SCMAS (Supply Chain Multi-agent Systems) \\
\hline Contribution & $\begin{array}{l}\text { A multi-agent architecture dedicated to negotiation and to production } \\
\text { planning and dynamic scheduling }\end{array}$ \\
\hline SC Problem & SC Scheduling; Negotiation \\
\hline Theoretical or Applied & $\mathrm{T}$ \\
\hline Application Sector & Computers industry \\
\hline Specific Implementation Toolkit & Yes (JADE) \\
\hline Methodological approach & NI \\
\hline APS Modules & NI \\
\hline Social Agent Organization & Some (a negotiation approach is proposed) \\
\hline Individual Agent Organization & Some (agents have defined individual roles) \\
\hline Authors & Feng, Helaakoski, Jurrens \& Kipinä (2007) \\
\hline Approach/Project & SteelNet \\
\hline Contribution & $\begin{array}{l}\text { A coalition framework for business and manufacturing networks } \\
\text { comprising an ontological engineering environment and a multi-agent } \\
\text { architecture. The d-APS is just part of a larger architecture, including } \\
\text { other elements such as CAPP and CAM, for example }\end{array}$ \\
\hline SC Problem & Manufacturing and SC Integration \\
\hline Theoretical or Applied & $\mathrm{T}$ \\
\hline Application Sector & Steel products \\
\hline Specific Implementation Toolkit & Yes (JADE) \\
\hline Methodological approach & NI \\
\hline APS Modules & $\mathrm{NI}$ \\
\hline Social Agent Organization & Some (some interaction mechanisms are studied) \\
\hline Individual Agent Organization & Some (an internal agent architecture is proposed) \\
\hline Authors & Frayret et al. (2007) \\
\hline Approach/Project & The experimentation planning platform \\
\hline Contribution & $\begin{array}{l}\text { A generic software architecture for development of an experimentation } \\
\text { environment to design and test distributed advanced planning and } \\
\text { scheduling systems }\end{array}$ \\
\hline SC Problem & SC planning \\
\hline Theoretical or Applied & TA \\
\hline Application Sector & Forest products industry \\
\hline Specific Implementation Toolkit & No (C\# - Microsoft.NET - and with ILOG CPLEX and ILOG SOLVER) \\
\hline Methodological approach & NI \\
\hline APS Modules & Yes (agents are specialized in different APS planning areas) \\
\hline Social Agent Organization & Some (some agents interactions protocols are identified) \\
\hline Individual Agent Organization & Some (agents planning capabilities) \\
\hline Authors & Ivanov, Kaeschel \& Sokolov (2007a) \\
\hline Approach/Project & Decentralised Integrated Modelling Approach (DIMA) \\
\hline Contribution & $\begin{array}{l}\text { Multi-disciplinary approach to model flexible application of various } \\
\text { modelling frameworks (analytical, simulation and heuristics) as well as } \\
\text { their combinations in the context of agile production networks }\end{array}$ \\
\hline SC Problem & SC Integration - named collaborative and agile networks \\
\hline Theoretical or Applied & $\mathrm{T}$ \\
\hline Application Sector & NI \\
\hline Specific Implementation Toolkit & NI \\
\hline Methodological approach & $\begin{array}{l}\text { Some (some methodological aspects are considered, as the definition of } \\
\text { conceptual models, mathematical models and simulation tools) }\end{array}$ \\
\hline APS Modules & NI \\
\hline Social Agent Organization & Yes (some general schema of agents interactions) \\
\hline Individual Agent Organization & Yes (some functional agent models for describing active elements) \\
\hline Authors & Ivanov, Arkhipov \& Sokolov (2007b) \\
\hline Approach/Project & NI \\
\hline Contribution & $\begin{array}{l}\text { It elaborates principles for creating complex quantitative models for SC } \\
\text { and Virtual Enterprises using concepts from control theory, system } \\
\text { theory, operations research and distributed artificial intelligence }\end{array}$ \\
\hline SC Problem & SC Planning and Control \\
\hline Theoretical or Applied & $\mathrm{T}$ \\
\hline Application Sector & $\mathrm{NI}$ \\
\hline Specific Implementation Toolkit & No (partially implemented using $\mathrm{C}++$ ) \\
\hline Methodological approach & $\begin{array}{l}\text { Some (some methodological aspects are considered, as the definition of } \\
\text { conceptual models, mathematical models and simulation tools) }\end{array}$ \\
\hline APS Modules & $\mathrm{NI}$ \\
\hline Social Agent Organization & $\mathrm{NI}$ \\
\hline Individual Agent Organization & Some (meta-models for SC planning and control) \\
\hline Authors & Jankowska, Kurbel \& Schreber (2007) \\
\hline Approach/Project & $\begin{array}{l}\text { Mobile Agent-based SCEM System (MASS) SCEM stands for Supply } \\
\text { Chain Event Management }\end{array}$ \\
\hline Contribution & $\begin{array}{l}\text { An architecture for a mobile SC event management system based on } \\
\text { mobile agents, Auto-ID technologies and mobile computing for linking } \\
\text { SC planning and SC execution }\end{array}$ \\
\hline SC Problem & SC Planning and Execution (SC Event Management) \\
\hline Theoretical or Applied & TA \\
\hline Application Sector & Bicycle Industry, but no details are provided \\
\hline Specific Implementation Toolkit & Yes (JADE) \\
\hline
\end{tabular}




\begin{tabular}{|c|c|}
\hline Methodological approach & NI \\
\hline APS Modules & NI \\
\hline Social Agent Organization & $\mathrm{NI}$ \\
\hline Individual Agent Organization & NI \\
\hline Authors & Labarthe et al. (2007) \\
\hline Approach/Project & $\mathrm{NI}$ \\
\hline Contribution & $\begin{array}{l}\text { An agent-based methodological framework for modelling and simulation } \\
\text { of SC }\end{array}$ \\
\hline SC Problem & General problems related to SCM \\
\hline Theoretical or Applied & TA \\
\hline Application Sector & Golf club industry \\
\hline Specific Implementation Toolkit & Yes (AnyLogic and Majorca) \\
\hline Methodological approach & Yes (the proposed framework is of methodological nature) \\
\hline APS Modules & $\mathrm{NI}$ \\
\hline Social Agent Organization & $\begin{array}{l}\text { Yes (a specific interaction schema is proposed - structural and dynamic } \\
\text { model) }\end{array}$ \\
\hline Individual Agent Organization & Yes (agent roles - cognitive and reactive - are explicitly defined) \\
\hline Authors & Lee \& Kumara (2007) \\
\hline Approach/Project & $\mathrm{NI}$ \\
\hline Contribution & $\begin{array}{l}\text { A decentralized coordination approach for dynamic lot-sizing in } \\
\text { distribution networks }\end{array}$ \\
\hline SC Problem & Coordination, information sharing and lot-sizing in distribution networks \\
\hline Theoretical or Applied & $\mathrm{T}$ \\
\hline Application Sector & NI \\
\hline Specific Implementation Toolkit & No (they used a Discrete-Event Simulator - not identified - and LINDO) \\
\hline Methodological approach & $\mathrm{NI}$ \\
\hline APS Modules & $\mathrm{NI}$ \\
\hline Social Agent Organization & Some (coordination mechanisms based on auctions/bidding strategies) \\
\hline Individual Agent Organization & Some (a lot sizing approach) \\
\hline Authors & Monteiro, Roy \& Anciaux (2007) \\
\hline Approach/Project & $\mathrm{NI}$ \\
\hline Contribution & $\begin{array}{l}\text { An heterarchical architecture for coordinating decisions in a multi-site } \\
\text { environment }\end{array}$ \\
\hline SC Problem & Coordination, SC planning, Negotiation \\
\hline Theoretical or Applied & TA \\
\hline Application Sector & Bronze tap production system \\
\hline Specific Implementation Toolkit & $\mathrm{NI}$ \\
\hline Methodological approach & NI \\
\hline APS Modules & $\mathrm{NI}$ \\
\hline Social Agent Organization & Some (cooperative negotiation models) \\
\hline Individual Agent Organization & Some (a Planner Agent and a Negotiator Agent) \\
\hline Authors & Orcun et al. (2007) \\
\hline Approach/Project & SCOPE (Supply chain optimization and protocol environment) \\
\hline Contribution & $\begin{array}{l}\text { A rapid-prototyping environment for simulating SC planning scenarios } \\
\text { employing APS technology }\end{array}$ \\
\hline SC Problem & SC planning, collaboration \\
\hline Theoretical or Applied & TA \\
\hline Application Sector & Consumer packaged goods industry \\
\hline Specific Implementation Toolkit & $\begin{array}{l}\text { No (they employed Excel with Visual Basic and Crystal Ball and they also } \\
\text { employed ILOG CPLEX) }\end{array}$ \\
\hline Methodological approach & NI \\
\hline APS Modules & Yes (Agents are specialized in different APS planning areas) \\
\hline Social Agent Organization & NI \\
\hline Individual Agent Organization & Some (different planning approaches for each agent) \\
\hline Authors & Shin (2007) \\
\hline Approach/Project & Collaborative coordination of distributed production planning (DPP) \\
\hline Contribution & $\begin{array}{l}\text { Collaborative coordination mechanism/heuristics based on information } \\
\text { sharing and on a coordinator/mediator for a distributed system }\end{array}$ \\
\hline SC Problem & Coordination, production planning \\
\hline Theoretical or Applied & $\mathrm{T}$ \\
\hline Application Sector & $\mathrm{NI}$ \\
\hline Specific Implementation Toolkit & $\mathrm{NI}$ \\
\hline Methodological approach & NI \\
\hline APS Modules & $\mathrm{NI}$ \\
\hline Social Agent Organization & Some (for coordination and collaboration only) \\
\hline Individual Agent Organization & Some (production planning model) \\
\hline Authors & Venkatadri \& Kiralp (2007) \\
\hline Approach/Project & DSOPP (Distributed Simulation Order Promising Platform) \\
\hline Contribution & $\begin{array}{l}\text { An agent-based architecture for order promising in a distributed network } \\
\text { employing optimization technology }\end{array}$ \\
\hline SC Problem & Order promising, SC planning \\
\hline Theoretical or Applied & $\mathrm{T}$ \\
\hline Application Sector & NI \\
\hline Specific Implementation Toolkit & No (OPL Studio 3.7 and Visual Studio 6.0) \\
\hline Methodological approach & $\mathrm{NI}$ \\
\hline APS Modules & $\mathrm{NI}$ \\
\hline Social Agent Organization & Some (order promising interaction schema) \\
\hline Individual Agent Organization & $\mathrm{NI}$ \\
\hline
\end{tabular}




\begin{tabular}{|l|l|}
\hline Authors & Yain-Whar, Edmond, Dumas \& Chong (2007) \\
\hline Approach/Project & UMTac-04 \\
\hline Contribution & $\begin{array}{l}\text { Comparison of two different strategies in SCM, namely buy-to-build and } \\
\text { build-to-order using an agent-based }\end{array}$ \\
\hline SC Problem & SC Planning \\
\hline Theoretical or Applied & T \\
\hline Application Sector & Computer industry \\
\hline Specific Implementation Toolkit & NI \\
\hline Methodological approach & NI \\
\hline APS Modules & NI \\
\hline Social Agent Organization & NI \\
\hline Individual Agent Organization & Some (different planning strategies) \\
\hline
\end{tabular}

Table 2. Studied works for the year 2007

\begin{tabular}{|c|c|}
\hline Authors & Forget et al. (2008) \\
\hline Approach/Project & Multi-Behaviour Agents for SC Planning \\
\hline Contribution & $\begin{array}{l}\text { An agent-based model employing multi-behaviour strategies for SC } \\
\text { planning, which are able to react differently according to stimuli from } \\
\text { the business environment }\end{array}$ \\
\hline SC Problem & SC planning; Coordination \\
\hline Theoretical or Applied & TA \\
\hline Application Sector & Lumber industry \\
\hline Specific Implementation Toolkit & $\begin{array}{l}\text { No (generic programming tools and optimization used ILOG SOLVER and } \\
\text { ILOG CPLEX) }\end{array}$ \\
\hline Methodological approach & NI \\
\hline APS Modules & NI \\
\hline Social Agent Organization & Some (two different coordination schemas were studied) \\
\hline Individual Agent Organization & Yes (different agent behaviours for SC planning) \\
\hline Authors & Jung, Chen \& Jeong (2008) \\
\hline Approach/Project & $\mathrm{NI}$ \\
\hline Contribution & $\begin{array}{l}\text { A decentralized supply chain planning framework based on minimal- } \\
\text { information sharing between the manufacturer and the third party } \\
\text { logistics provider }\end{array}$ \\
\hline SC Problem & Planning, Collaboration, Information Sharing \\
\hline Theoretical or Applied & $\mathrm{T}$ \\
\hline Application Sector & NI \\
\hline Specific Implementation Toolkit & No (only ILOG-OPL Studio) \\
\hline Methodological approach & $\mathrm{NI}$ \\
\hline APS Modules & $\mathrm{NI}$ \\
\hline Social Agent Organization & Some (a simple information sharing schema) \\
\hline Individual Agent Organization & Some (some decision models for distribution and production planning) \\
\hline Authors & Lau, Li, Song \& Kwok (2008) \\
\hline Approach/Project & $\mathrm{NI}$ \\
\hline Contribution & $\begin{array}{l}\text { A multi-agent system where agents are subject to an adjustable } \\
\text { autonomy, which is changed during runtime as a response to } \\
\text { uncertainties from the environment. Also, a coalition formation approach } \\
\text { is employed to establish global coherence through negotiation }\end{array}$ \\
\hline SC Problem & SC adaptability for entities' autonomy \\
\hline Theoretical or Applied & TA \\
\hline Application Sector & Defence industry \\
\hline Specific Implementation Toolkit & NI \\
\hline Methodological approach & NI \\
\hline APS Modules & NI \\
\hline Social Agent Organization & Some (a coalition formation approach) \\
\hline Individual Agent Organization & Some (individuals' autonomy) \\
\hline Authors & Lin, Kuo \& Lin (2008) \\
\hline Approach/Project & NegoGA (Negotiation and Genetic Algorithm) \\
\hline Contribution & $\begin{array}{l}\text { A distributed coordination mechanism that integrates negotiation } \\
\text { techniques with genetic algorithm to plan quasi-optimal order fulfilment }\end{array}$ \\
\hline SC Problem & Coordination \\
\hline Theoretical or Applied & T \\
\hline Application Sector & Modul manufacturing \\
\hline Specific Implementation Toolkit & Yes (JADE) \\
\hline Methodological approach & $\mathrm{NI}$ \\
\hline APS Modules & NI \\
\hline Social Agent Organization & Some (a negotiation approach) \\
\hline Individual Agent Organization & $\mathrm{NI}$ \\
\hline Authors & Paolucci et al. (2008) \\
\hline Approach/Project & Supply Chain Operations Planning (SCOP) System \\
\hline Contribution & A d-APS framework for Small and Medium Enterprises \\
\hline SC Problem & SC Planning (Sales \& Operations Planning) \\
\hline Theoretical or Applied & $\mathrm{T}$ \\
\hline Application Sector & NI \\
\hline Specific Implementation Toolkit & NI \\
\hline Methodological approach & NI \\
\hline
\end{tabular}




\begin{tabular}{|l|l|}
\hline APS Modules & NI \\
\hline Social Agent Organization & $\begin{array}{l}\text { Some (a bidding approach with a negotiation mechanism based on } \\
\text { Contract-Net Protocol) }\end{array}$ \\
\hline Individual Agent Organization & Some (some decision variables are explicitly used by the mediator) \\
\hline Authors & Santa-Eulalia et al. (2008) \\
\hline Approach/Project & NI \\
\hline Contribution & $\begin{array}{l}\text { A conceptual framework for modelling agent-based simulation for SC } \\
\text { planning }\end{array}$ \\
\hline SC Problem & SC Planning \\
\hline Theoretical or Applied & TA \\
\hline Application Sector & Lumber industry \\
\hline Specific Implementation Toolkit & $\begin{array}{l}\text { No (generic programming tools and optimization used ILOG SOLVER and } \\
\text { ILOG CPLEX) }\end{array}$ \\
\hline Methodological approach & Yes (The main contribution is of methodological nature) \\
\hline APS Modules & $\begin{array}{l}\text { Some (they explain some traditional modules, such as procurement, } \\
\text { scheduling, inventory projection and forecasting) }\end{array}$ \\
\hline Social Agent Organization & NI \\
\hline Individual Agent Organization & NI \\
\hline
\end{tabular}

Table 3. Studied works for the year 2008

\begin{tabular}{|c|c|}
\hline Authors & Benisch, Sardinha, Andrews, Ravichandran \& Sadeh (2009) \\
\hline Approach/Project & CMieux \\
\hline Contribution & $\begin{array}{l}\text { An agent approach called CMieux in the context of the TAC SCM (Trading } \\
\text { Agent Competition). It implements adaptive strategies to support the } \\
\text { integration of procurement, bidding and planning functionality. They } \\
\text { performed experiments to demonstrate empirically the performance of } \\
\text { their approach }\end{array}$ \\
\hline SC Problem & SC planning; Coordination \\
\hline Theoretical or Applied & $\mathrm{T}$ \\
\hline Application Sector & Computer industry \\
\hline Specific Implementation Toolkit & $\mathrm{NI}$ \\
\hline Methodological approach & NI \\
\hline APS Modules & Yes (the notion of d-APS is identified) \\
\hline Social Agent Organization & $\mathrm{NI}$ \\
\hline Individual Agent Organization & Some (agents mechanism for SC planning) \\
\hline Authors & Cid-Yanez, Frayret \& Léger (2009) \\
\hline Approach/Project & (FEPP) FORAC Experimental Planning Platform \\
\hline Contribution & $\begin{array}{l}\text { Analysis of some demand-driven planning approaches that propagate } \\
\text { demand information upstream the supply chain }\end{array}$ \\
\hline SC Problem & SC Planning \\
\hline Theoretical or Applied & TA \\
\hline Application Sector & Lumber industry \\
\hline Specific Implementation Toolkit & No (C\# - Microsoft. NET - and with ILOG CPLEX and ILOG SOLVER) \\
\hline Methodological approach & NI \\
\hline APS Modules & Yes (Agents are specialized in different APS planning areas) \\
\hline Social Agent Organization & NI \\
\hline Individual Agent Organization & Some (different planning approaches for each agent) \\
\hline Authors & Gaudreault, Forget, Frayret, Rousseau \& D'Amours (2009) \\
\hline Approach/Project & NI \\
\hline Contribution & $\begin{array}{l}\text { Three agent-specific mathematical models to plan and schedule a } \\
\text { softwood SC composed of sawing, drying and finishing activities. Specific } \\
\text { coordination mechanisms are also proposed to assure that the resulting } \\
\text { plans are coherent with each other }\end{array}$ \\
\hline SC Problem & SC Planning; coordination \\
\hline Theoretical or Applied & TA \\
\hline Application Sector & Softwood lumber \\
\hline Specific Implementation Toolkit & No (C\# - Microsoft. NET - and with ILOG CPLEX and ILOG SOLVER) \\
\hline Methodological approach & NI \\
\hline APS Modules & Some (specific modules for three SC entities at the operational level) \\
\hline Social Agent Organization & Some (a coordination mechanism) \\
\hline Individual Agent Organization & Some (specific modules for the three SC units) \\
\hline Authors & Ivanov (2009) \\
\hline Approach/Project & DIMA (decentralized integrated modelling approach) \\
\hline Contribution & $\begin{array}{l}\text { A novel approach for comprehensive multi-disciplinary modelling of } \\
\text { distributed large-scale business systems with decentralized decision- } \\
\text { making and control }\end{array}$ \\
\hline SC Problem & SC planning and control \\
\hline Theoretical or Applied & $\mathrm{T}$ \\
\hline Application Sector & NI \\
\hline Specific Implementation Toolkit & NI \\
\hline Methodological approach & $\begin{array}{l}\text { Yes (a macro approach covering conceptual } \\
\text { modelling, mathematical modelling, and software development) }\end{array}$ \\
\hline APS Modules & NI \\
\hline Social Agent Organization & NI \\
\hline Individual Agent Organization & NI \\
\hline
\end{tabular}




\begin{tabular}{|c|c|}
\hline Authors & Lemieux, D'Amours, Gaudreault \& Frayret (2009) \\
\hline Approach/Project & (FEPP) FORAC Experimental Planning Platform \\
\hline Contribution & A multi-agent simulation environment for SC planning \\
\hline SC Problem & SC Planning \\
\hline Theoretical or Applied & TA \\
\hline Application Sector & Lumber industry \\
\hline Specific Implementation Toolkit & No (C\# - Microsoft. NET - and with ILOG CPLEX and ILOG SOLVER) \\
\hline Methodological approach & NI \\
\hline APS Modules & Some (they developed some operational planning modules) \\
\hline Social Agent Organization & Some (conversation mechanisms are proposed) \\
\hline Individual Agent Organization & Some (different planning approaches for each agent) \\
\hline Authors & Pan, Leung, Moon \& Yeung (2009) \\
\hline Approach/Project & $\mathrm{NI}$ \\
\hline Contribution & $\begin{array}{l}\text { A UML-based modelling approach for representing SC and a genetic } \\
\text { algorithm and fuzzy inference mechanism for determining a reorder point } \\
\text { in uncertain contexts }\end{array}$ \\
\hline SC Problem & Coordination, order promising \\
\hline Theoretical or Applied & $\mathrm{T}$ \\
\hline Application Sector & Fashion industry \\
\hline Specific Implementation Toolkit & No (Matlab) \\
\hline Methodological approach & $\mathrm{NI}$ \\
\hline APS Modules & $\mathrm{NI}$ \\
\hline Social Agent Organization & Some (interactions are indicated in general terms) \\
\hline Individual Agent Organization & Some (a model is created for calculating reorder points) \\
\hline Authors & Santa-Eulalia et al. (2009b) \\
\hline Approach/Project & (FEPP) FORAC Experimental Planning Platform \\
\hline Contribution & Testing different SC strategies in an agent-based environment \\
\hline SC Problem & SC Planning and Control \\
\hline Theoretical or Applied & TA \\
\hline Application Sector & Forest products industry \\
\hline Specific Implementation Toolkit & No (C\# - Microsoft. NET - and with ILOG CPLEX and ILOG SOLVER) \\
\hline Methodological approach & NI \\
\hline APS Modules & Some (Agents are specialized in different APS planning areas) \\
\hline Social Agent Organization & Some (a coordination mechanism) \\
\hline Individual Agent Organization & Some (different planning approaches for each agent) \\
\hline Authors & Silva et al. (2009) \\
\hline Approach/Project & $\mathrm{NI}$ \\
\hline Contribution & $\begin{array}{l}\text { Proposes a distributed optimization framework for SC planning based on a } \\
\text { meta-heuristic called ant colony optimization }\end{array}$ \\
\hline SC Problem & Cooperation \\
\hline Theoretical or Applied & TA \\
\hline Application Sector & Computer industry \\
\hline Specific Implementation Toolkit & No (Matlab) \\
\hline Methodological approach & NI \\
\hline APS Modules & NI \\
\hline Social Agent Organization & Some (specific information sharing schemas) \\
\hline Individual Agent Organization & Some (agents dedicated to supply, logistics and distribution were defined) \\
\hline
\end{tabular}

Table 4. Studied works for the year 2009

\begin{tabular}{|l|l|}
\hline Authors & Chan \& Chan (2010) \\
\hline Approach/Project & NI \\
\hline Contribution & $\begin{array}{l}\text { An adaptive coordination strategy for improving fill rate while reducing } \\
\text { costs without using information sharing }\end{array}$ \\
\hline SC Problem & Coordination \\
\hline Theoretical or Applied & T \\
\hline Application Sector & NI \\
\hline Specific Implementation Toolkit & No (Java) \\
\hline Methodological approach & NI \\
\hline APS Modules & NI \\
\hline Social Agent Organization & Some (coordination mechanisms) \\
\hline Individual Agent Organization & Some (decision models for two-echelon SC) \\
\hline Authors & Ivanov et al. (2010) \\
\hline Approach/Project & A-SCM (Adaptive SCM) \\
\hline Contribution & $\begin{array}{l}\text { A multi-structural framework (models and tools) for the planning and } \\
\text { control of adaptive SC using principles from control theory, operations } \\
\text { research and agent-based modelling }\end{array}$ \\
\hline SC Problem & SC planning, coordination \\
\hline Theoretical or Applied & T \\
\hline Application Sector & They mention that it was applied to special machinery building and textile \\
branches, but these cases are not discussed in the paper
\end{tabular}




\begin{tabular}{|c|c|}
\hline Authors & Karam, Tranvouez, Espinasse \& Ferrarini et al. (2010) \\
\hline Approach/Project & NI \\
\hline Contribution & $\begin{array}{l}\text { A methodological framework for modelling agent-based simulation for SC } \\
\text { planning based on conceptual and operational models }\end{array}$ \\
\hline SC Problem & General problems related to SCM \\
\hline Theoretical or Applied & TA \\
\hline Application Sector & Golf club industry \\
\hline Specific Implementation Toolkit & Yes (Majorca and Analogic) \\
\hline Methodological approach & Yes (The main contribution is of methodological nature) \\
\hline APS Modules & NI \\
\hline Social Agent Organization & Yes (several interactions possibilities are explicitly mapped) \\
\hline Individual Agent Organization & Yes (different agents' roles are identified conceptually) \\
\hline Authors & Kim \& Cho (2010) \\
\hline Approach/Project & NI \\
\hline Contribution & $\begin{array}{l}\text { Negotiation approach for SC formation using mediators. They compared } \\
\text { their approach with a heuristic and centralized one }\end{array}$ \\
\hline SC Problem & Negotiation \\
\hline Theoretical or Applied & $\mathrm{T}$ \\
\hline Application Sector & NI \\
\hline Specific Implementation Toolkit & No $(\mathrm{C} / \mathrm{C}++$, ILOG CPLEX) \\
\hline Methodological approach & NI \\
\hline APS Modules & NI \\
\hline Social Agent Organization & Some (a negotiation approach is proposed) \\
\hline Individual Agent Organization & Some (scheduling models for agents) \\
\hline Authors & Santa-Eulalia et al. (2010) \\
\hline Approach/Project & $\begin{array}{l}\text { FAMASS (FORAC Architecture for Modelling Agent-based Simulation Supply } \\
\text { Chain Planning) }\end{array}$ \\
\hline Contribution & $\begin{array}{l}\text { A methodological framework for modelling agent-based simulation for SC } \\
\text { planning applied in the forest products industry }\end{array}$ \\
\hline SC Problem & General problems related to SCM and agents \\
\hline Theoretical or Applied & TA \\
\hline Application Sector & Lumber industry \\
\hline Specific Implementation Toolkit & $\begin{array}{l}\text { No (generic programming tools and optimization used ILOG SOLVER and } \\
\text { ILOG CPLEX) }\end{array}$ \\
\hline Methodological approach & Yes (The main contribution is of methodological nature) \\
\hline APS Modules & Yes (A specific modelling schema is proposed, which is called SC cube) \\
\hline Social Agent Organization & Yes (a specific modelling schema is proposed) \\
\hline Individual Agent Organization & Yes (a specific modelling schema is proposed) \\
\hline
\end{tabular}

Table 5. Studied works for the year 2010

The following sub-sections discuss the main criteria surveyed.

\subsection{Main Contributions}

Contributions in the domain cover dissimilar topics. For example, several papers propose agent-based architectures (Frayret et al., 2007; Andreev et al., 2007; Feng et al., 2007; Monteiro et al., 2007; Venkatadri \& Kiralp, 2007), some deal with the famous TAC - Trade Agent Competition (Andrews et al., 2007; Si, Edmond, Dumas \& Chong, 2007; Benisch et al., 2009), certain approaches propose coordination and information-sharing mechanisms (Lee \& Kumara, 2007), others focus on mathematical models for agents (Gaudreault et al., 2009), a number use an agent-based environment only as a testbed to test SC strategies (Cid-Yanez et al., 2009; Santa-Eulalia et al., 2009b), and finally some propose agent-based methodological frameworks (e.g. Karam et al., 2010; Santa-Eulalia et al., 2010; Labarthe et al., 2007).

It was observed that the terms framework, architecture, approaches and methodology were very frequently employed in many studies to define the 
contribution of the papers, but no definition was provided for them. For example, in the modelling area (particularly in the Enterprise Modelling; Vernadat, 1996), these terms can have different meanings, but the surveyed works mostly neglect to specify the nature of their contribution. This is probably an indication that the surveyed area is still an emerging domain requiring some organization.

\section{$\underline{\text { SC Problems }}$}

Several SC problems were identified: general problems related to SCM, manufacturing and SC integration, SC planning, scheduling, control and execution, cooperation, coordination, negotiation, information sharing, SC adaptability, order promising, and multi-level lot-sizing.

It is possible to affirm that three macro categories exist in this area, covering most of the papers: 1) Relationships in SC, including the following categories: coordination, cooperation, information sharing, negotiation and integration; 2) Production Planning and Control, comprising the following sub-categories: SC planning, scheduling, control and execution; 3) Others, including papers related to general problems in SCM and agents, as well as one about SC adaptability.

When considering possible repetition (i.e. when a paper can be classified in more than one macro category), it is possible to see that: 17 papers (50\%) are in the macro category Relationships in SC (including Chan \& Chan, 2010; Lin et al., 2008; Lee \& Kumara, 2007); 22 papers (65\%) are related to Production Planning and Control (Lemieux et al., 2009; Jankowska et al., 2007; Orcun et al., 2007); and finally, there are only four papers $(12 \%)$ in the third macro category (i.e., three papers related to general problems: Karam et al., 2010; Santa-Eulalia et al., 2010; Labarthe et al., 2007 - and one paper about SC adaptability, i.e. Lau et al., 2008). Figure 3 summarizes these findings.

This led us to believe that d-APS researchers are focusing mostly on two mainstream subjects (Relationships in SC and PPC), and that there is some interesting room for other domains. For example, problems related to SC governance, sustainability, adaptability, network design and other domains are lacking in the recent literature.

\section{Applications}

Among the selected 34 papers, 18 (53\%) are of a theoretical nature (Ivanov, 2009) and $16(47 \%)$ provide real applications (Cid-Yanez et al., 2009). Seven of the 
theoretical papers $(21 \%)$ also illustrate their approach through conceptual (not real) industrial applications (Si et al., 2007).

Despite the fact that applications are usually considered relevant for having papers published in prestigious journals and conferences, more than half of them (18) do not provide real applications and $12(35 \%)$ do not provide any at all. Among those manuscripts presenting some kind of application, most of them (28) are demonstrations (e.g. proofs of concept) that are not linked with an industrial-scale situation. None of the papers present mature applications being commercialized or close to the market. This indicates that, so far. d-APS systems are mostly at laboratorial stages and that many efforts need to be made in order to gain more practical insights.

The last four tables also surveyed the application sector of the 16 studies concerned, which are: airport logistics, laundry, pharmaceuticals, forest products, bicycles, golf clubs, defence, bronze taps, packing, computers and toys. In the case of theoretical papers employing conceptual industrial cases, the following sectors were found: computers, steel, mould and fashion. It is interesting to note that eight manuscripts are about the forest products industry. This indicates that the application is quite diversified, hence enriching the domain, although many applications are of an academic nature.

\section{Toolkits and Methodologies}

Modelling toolkits are not employed massively, since only seven manuscripts (20\%) out of 34 utilize a known toolkit: four use JADE, one works with AnyLogic and two employ together Majorca and Anylogic.

Among those works not mentioning any specialized agent toolkit, it was observed that generic languages are usually employed (mainly $\mathrm{C}, \mathrm{C} / \mathrm{C}++$, and visual basic) connected to some optimization system (e.g. ILOG SOLVER and CPLEX). Other technologies used for implementation are ILOG-OPL Studio, LINDO, Excel, Crystal Ball, some discrete-event simulation tool, and Visual Studio. No correlation was identified between the methodological aspects and the agent toolkits.

In terms of methodological aspects, 27 papers (79\%) out of 34 do not explicitly mention the use of them. On the other hand, a small quantity of two (6\%) papers (Ivanov et al., 2007a; Ivanov et al., 2007b) present some indications that they were inspired by methodological aspects, such as the definition of conceptual models, mathematical models and simulation tools. Only five (15\%) papers 
explicitly present methodological elements and four contributions are of a methodological nature (Karam et al., 2010; Santa-Eulalia et al., 2010; Ivanov, 2009; Labarthe et al., 2007). The methodological aspects of these five works will be detailed in subsection 4.3 .

\section{APS Functions and Modules}

Despite the fact that the studied works being reviewed can be classified as dealing with d-APS systems according to our definition, few articles (i.e. 9 out of 34, representing 26\%) detail (i.e. Yes and Some) APS modules. Some of them present agents specialized in traditional APS modules, such as procurement, scheduling, inventory and forecasting (Benisch et al., 2009); others present agents specialized in specific industrial domains (e.g. operational planning for sawing, drying and finishing operations, such as Cid-Yanez et al., 2009, Lemieux et al., 2009, and Gaudreault et al., 2009); and in one specific case a specialized modelling schema is proposed to explicitly represent a d-APS system (Santa-Eulalia et al., 2010).

The evaluation of this criterion allows us to believe that a complete and integrated view of d-APS is still not properly covered in the reviewed literature. Most of the works do not intend to propose a generic architecture for d-APS systems, specialized in specific domains. At the present time, almost all of the papers deal with agent-based SC planning and scheduling using optimization approaches without explicitly declaring that APS (or d-APS) technology is being used. This indicated that d-APS is still a new research domain which is not uniformly defined.

\section{Social and Individual Agents Issues}

When dealing with d-APS, two facets of these systems have to be considered: social and individual abilities of the multi-agent system.

In terms of the social aspects, it was not possible to clearly identify them in 10 manuscripts $(29 \%)$. Despite the fact that in some cases terms such as communication and conversation are mentioned, they do not provide any approach for modelling social aspects of the agent society. For example, Jankowska et al. (2007) is much more dedicated to the layered technical architecture and the main computing technologies it integrates.

On the other hand, 20 works (59\%) are classified as proposing "some" discussion about social aspects. They do not provide any complete modelling approach to identify and simulate several different types of social structures or social protocols, but they address these aspects somehow; sometimes one paper just mentions or 
uses one or two social aspects in a limited way; occasionally they take one specific aspect (e.g. negotiation) and thoroughly explore it by proposing protocols, for example. For instance, Kim \& Cho (2010) present an approach based on cooperative relationships, information sharing and negotiation.

Finally, four papers (12\%) are classified as "yes" because they propose a dedicated set of modelling schemas to capture different social facets of d-APS systems. Karam et al. (2010) provide an appropriate set of abstractions to identify, develop and describe the organizational structure of an SC as well as the dynamic relations between the entities that make up an SC. Santa-Eulalia et al. (2010) also present a specialized modelling schema, called Social Agent Organization Analysis, to capture different social structures and protocols. Ivanov et al. (2010) discuss an approach for coping with a multiple structure design and changeability of structural parameters due to different factors at all stages of the supply chain life cycle. Labarthe et al. (2007) created a dynamic and structural model based on responsibility networks in SC.

Using exactly the same logic employed for the social aspects, the 34 surveyed papers revealed that the individual aspects of the agent society are not considered in seven (21\%) manuscripts. E.g., Andreev et al. (2007) propose a concept called Open Demand and Resource Networks, which dynamically matches demands and resources. This can be used to define a variety of individuals in a network, but their individual aspects (e.g. roles, internal architectures, etc.) are not identified.

In 22 papers $(65 \%)$ out of 34 , some individual aspects were treated. For example, some works approach one (or more) individual aspects of each agent, such as Lau et al. (2008), who propose an approach to manage the agent's individual autonomy according to environmental changes.

A more complete solution suggesting detailed ways of modelling several individual aspects of SC was found in only five papers (15\%). Karam et al. (2010) provide some abstractions to define agents' behaviours that can be of reactive, deliberative or hybrid nature. Santa-Eulalia et al. (2010) also propose a specialized modelling schema, called Individual Agent Organization Analysis, to capture different individual characteristics. Ivanov et al. (2010) put forward functional agent models for describing active elements. Based on the actor-agent paradigm, Labarthe et al. (2007) suggest two individual roles for agents, i.e. cognitive and reactive, with some encapsulation principles and a behavioural representation method. 
It is interesting to note that three out of four papers covering social and individual aspects of agents' society also deal with methodological approaches. The exception is Ivanov et al. (2010), but these authors do use methodological elements in some of their previous works.

Figure 3 summarizes the main findings of the studied works.

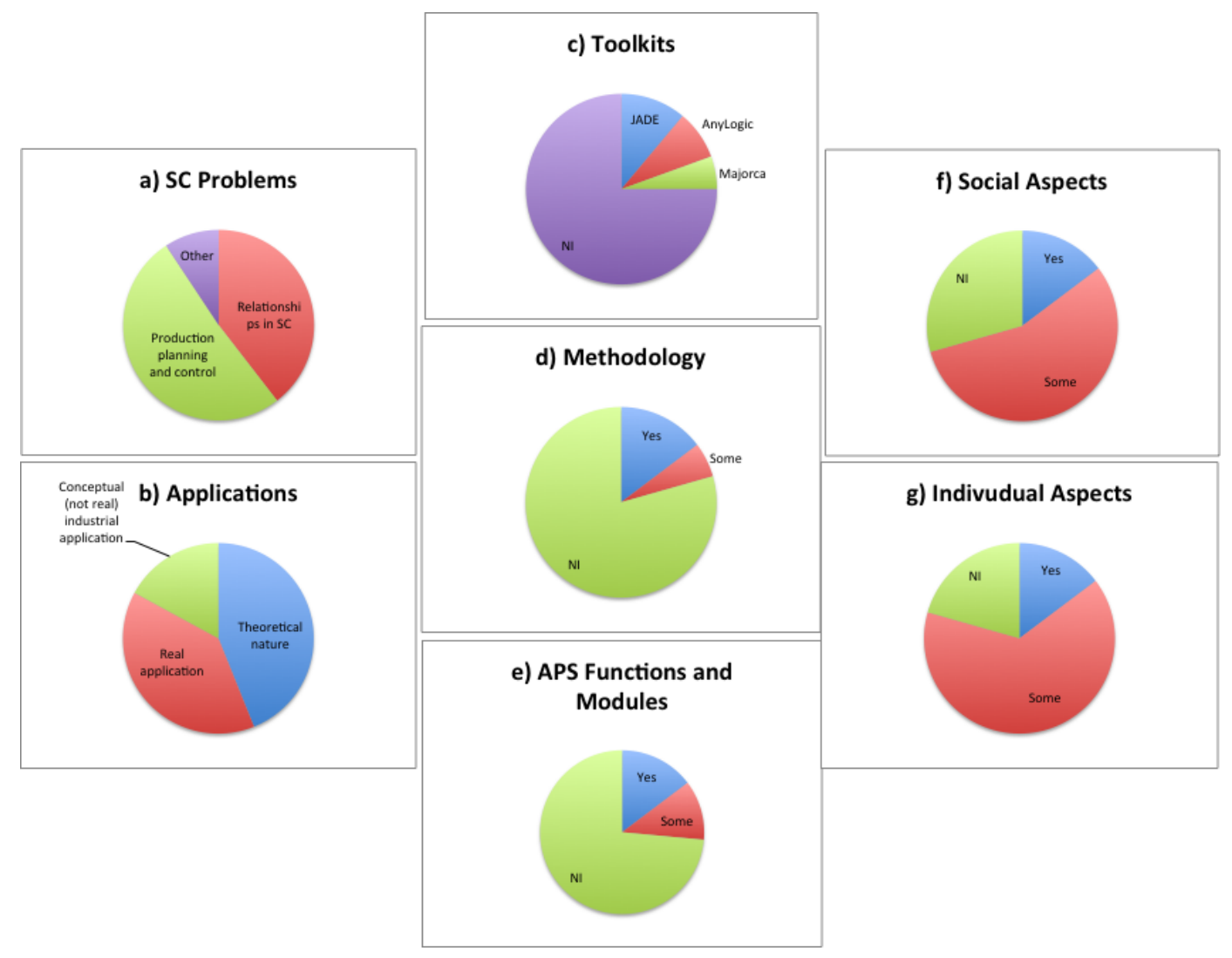

Figure 3. Summarizing the main findings of the studied works

\subsection{Methodological Frameworks for Modelling d-APS}

This section discusses the papers classified as somehow tackling methodological aspects. In order to do so, specific aspects to perform a descriptive evaluation were identified. They are:

- Modelling Phases: it was verified whether the framework adheres to the methodology for simulation of distributed systems developed by Galland et al. (2003), comprising the following traditional development phases: i) analysis: an abstract description of the modelled supply chain planning system containing the simulation requirements, in which the functionalities of simulation are identified and described in general terms; ii) specification: translation of the information derived from the analysis into a formal model. 
As the analysis phase does not necessarily allow the obtaining of a formal model, the specification examines the analysis requirements and builds a model based on a formal approach; iii) design: creation of a dataprocessing model that describes the specification model in more detail. In the case of an agent-based system, design models are close to how agents operate.

- Modelling Levels: the modelling levels comprise two issues: i) supply chain: refers to the supply chain planning problem, i.e. the business viewpoint; ii) agent: the supply chain domain problem is translated into an agent-based view; i.e. the technical viewpoint.

- Descriptive Evaluation: this part of the evaluation follows the Karageorgos \& Mehandjiev (2004) approach, as explained in subsection 3. In this case, only 8 out of 12 proposed criteria were evaluated, since 4 of them were not present in any surveyed work. They are: heuristics support, non-functional aspect, design automation, and tool support.

- Modelling Formalism: the integration of specific modelling formalisms in the methodological frameworks was verified.

Previously in step 2, seven works proposing methodological frameworks were identified. Due to their similarities, these works were assembled into four groups: Karam et al. (2010), FAMASS (Santa-Eulalia et al., 2010 and Santa-Eulalia et al., 2008) DIMA (Ivanov 2009; Ivanov et al., 2007a; and Ivanov et al., 2007b), and Labarthe et al. (2007). Table 6 summarizes the descriptive evaluation.

\begin{tabular}{|c|c|c|c|c|c|}
\hline & \multicolumn{3}{|c|}{ Methodological Phases } & \multicolumn{2}{|c|}{ Modelling Levels } \\
\hline Approach & Analysis & Specification & Design & $\begin{array}{l}\text { Domain models } \\
\text { (SC Planning and } \\
\text { Control) }\end{array}$ & Agent models \\
\hline $\begin{array}{l}\text { Karam et } \\
\text { al. } \\
(2010)\end{array}$ & NI & $\begin{array}{l}\text { The phase called Conceptual } \\
\text { Modelling generates models } \\
\text { for roles and organization, } \\
\text { which are not of executable } \\
\text { nature }\end{array}$ & $\begin{array}{l}\text { The phase called } \\
\text { Operational Modelling } \\
\text { generates the } \\
\text { executable models }\end{array}$ & NI & $\begin{array}{l}\text { Three models: } \\
\text { CROM (Conceptual } \\
\text { Role Organization } \\
\text { Model), CAOM } \\
\text { (Conceptual Agent } \\
\text { Organization Model) } \\
\text { and OPAM } \\
\text { (Operational Agent } \\
\text { Model) } \\
\end{array}$ \\
\hline FAMASS & $\begin{array}{l}\text { This is the main } \\
\text { contribution of } \\
\text { this work. } \\
\text { Several } \\
\text { reference models } \\
\text { are provided to } \\
\text { define functional } \\
\text { requirements for } \\
\text { simulation }\end{array}$ & $\begin{array}{l}\text { They do not propose } \\
\text { dedicated models for } \\
\text { specification, but they } \\
\text { employ Labarthe et al.'s } \\
\text { ( } 2007) \text { to generate } \\
\text { specification models from } \\
\text { the stated requirements. A } \\
\text { set of conversion rules is } \\
\text { proposed to derive } \\
\text { specification models from } \\
\text { their analysis }\end{array}$ & $\begin{array}{l}\text { Similarly to } \\
\text { specification, they } \\
\text { propose a set of } \\
\text { conversion rules to } \\
\text { translate analysis } \\
\text { requirements into } \\
\text { design models in } \\
\text { accordance with } \\
\text { Labarthe et al. (2007) }\end{array}$ & $\begin{array}{l}\text { Two approaches } \\
\text { are proposed: } \\
\text { one for defining } \\
\text { the simulation } \\
\text { problem and } \\
\text { another one for } \\
\text { identifying } \\
\text { functional } \\
\text { requirements for } \\
\text { the distributed } \\
\text { planning system }\end{array}$ & $\begin{array}{l}\text { Two approaches are } \\
\text { also proposed: one } \\
\text { covering the social } \\
\text { organization } \\
\text { (structure and } \\
\text { protocols) and } \\
\text { another for the } \\
\text { individual agents' } \\
\text { abilities }\end{array}$ \\
\hline
\end{tabular}




\begin{tabular}{|c|c|c|c|c|c|}
\hline & \multicolumn{3}{|c|}{ Methodological Phases } & \multicolumn{2}{|c|}{ Modelling Levels } \\
\hline Approach & Analysis & Specification & Design & $\begin{array}{l}\text { Domain models } \\
\text { (SC Planning and } \\
\text { Control) }\end{array}$ & Agent models \\
\hline DIMA & NI & $\begin{array}{l}\text { The separation between } \\
\text { specification and design } \\
\text { phases is not clear. } \\
\text { However, they propose } \\
\text { modelling approaches for } \\
\text { network design, adaptive } \\
\text { planning and control, and } \\
\text { network control. These } \\
\text { approaches can potentially } \\
\text { support specification and } \\
\text { design phases }\end{array}$ & $\begin{array}{l}\text { Two contributions can } \\
\text { be identified as being } \\
\text { part of thedesign } \\
\text { phase: i) a general } \\
\text { indication on how the } \\
\text { decision models work } \\
\text { for planning, } \\
\text { monitoring and } \\
\text { reconfiguration; ii) a } \\
\text { macro schema for the } \\
\text { MAS architecture }\end{array}$ & $\begin{array}{l}\text { They propose } \\
\text { conceptual } \\
\text { models for } \\
\text { decision-making, } \\
\text { including } \\
\text { planning, } \\
\text { execution and } \\
\text { stability } \\
\text { recovery/reconfi } \\
\text { guration }\end{array}$ & $\begin{array}{l}\text { It proposes a } \\
\text { functional agent } \\
\text { model for describing } \\
\text { active elements, a } \\
\text { general schema for } \\
\text { agents' interactions } \\
\text { for customer order } \\
\text { execution. Also, a } \\
\text { general MAS } \\
\text { functional } \\
\text { architecture is } \\
\text { proposed }\end{array}$ \\
\hline $\begin{array}{l}\text { Labarthe } \\
\text { et al. } \\
\text { (2007) }\end{array}$ & NI & $\begin{array}{l}\text { The Conceptual Level, } \\
\text { leading to the elaboration of } \\
\text { the Domain Model and the } \\
\text { Conceptual Agent Model }\end{array}$ & $\begin{array}{l}\text { The Operational } \\
\text { Level, which delimits } \\
\text { how the agent-based } \\
\text { system will work on a } \\
\text { simulation platform }\end{array}$ & $\begin{array}{l}\text { A specific } \\
\text { Domain Model is } \\
\text { proposed for SC } \\
\text { and mass } \\
\text { customization }\end{array}$ & $\begin{array}{l}\text { A Conceptual Agent } \\
\text { Model and an } \\
\text { Operational Agent } \\
\text { Model are specific } \\
\text { agent-dedicated } \\
\text { modelling } \\
\text { approaches }\end{array}$ \\
\hline $\begin{array}{l}\text { Karam et } \\
\text { al. } \\
(2010)\end{array}$ & $\begin{array}{l}\text { Only three types } \\
\text { of agent } \\
\text { architectures are } \\
\text { allowed: } \\
\text { cognitive, } \\
\text { reactive and } \\
\text { hybrid. The } \\
\text { methodology } \\
\text { proposes three } \\
\text { modelling steps } \\
\text { with specific } \\
\text { modelling rules }\end{array}$ & $\begin{array}{l}\text { Agents roles and collective } \\
\text { behaviours are explicitly } \\
\text { identified }\end{array}$ & $\begin{array}{l}\text { Design perspective is } \\
\text { top-down, with no } \\
\text { support for reuse }\end{array}$ & $\begin{array}{l}\text { Generality is } \\
\text { high. } \\
\text { Abstractabily is } \\
\text { present, with } \\
\text { three major } \\
\text { abstract levels } \\
\text { (conceptual, } \\
\text { operational and } \\
\text { exploitation) }\end{array}$ & $\begin{array}{l}\text { AUML, RCA } \\
\text { (Tranvouez, 2006) }\end{array}$ \\
\hline FAMASS & $\begin{array}{l}\text { It does not limit } \\
\text { the agent } \\
\text { architecture one } \\
\text { can employ. It } \\
\text { proposes four } \\
\text { phases with } \\
\text { several steps and } \\
\text { dedicated } \\
\text { modelling } \\
\text { guidelines }\end{array}$ & $\begin{array}{l}\text { Agents roles and collective } \\
\text { behaviours are explicitly } \\
\text { identified }\end{array}$ & $\begin{array}{l}\text { The design } \\
\text { perspective is mostly } \\
\text { a top-down approach, } \\
\text { but a bottom-up is } \\
\text { allowed. There is no } \\
\text { support for reuse }\end{array}$ & $\begin{array}{l}\text { It presents high } \\
\text { generality in d- } \\
\text { APS context. } \\
\text { Also, } \\
\text { abstractability is } \\
\text { present through } \\
\text { four modelling } \\
\text { levels (domain, } \\
\text { agent, } \\
\text { infrastructure } \\
\text { and simulation) }\end{array}$ & UML, AUML \\
\hline DIMA & $\begin{array}{l}\text { Open } \\
\text { architecture, no } \\
\text { agent type is } \\
\text { favoured. Only } \\
\text { general } \\
\text { engineering } \\
\text { lifecycle phases } \\
\text { (conceptual } \\
\text { model, } \\
\text { mathematical } \\
\text { model, and } \\
\text { simulation tool) }\end{array}$ & $\begin{array}{l}\text { Some agent roles are } \\
\text { formally identified (for } \\
\text { adaptive planning and } \\
\text { control). A collective } \\
\text { behaviour is not explicitly } \\
\text { detailed, only general } \\
\text { indications are provided }\end{array}$ & $\begin{array}{l}\text { The design } \\
\text { perspective is not } \\
\text { clear. There is no } \\
\text { support for reuse }\end{array}$ & $\begin{array}{l}\text { It is specialized } \\
\text { in virtual } \\
\text { enterprises and } \\
\text { collaborative } \\
\text { networks } \\
\text { (defined as a } \\
\text { special type of } \\
\text { SC), but almost } \\
\text { all notions can } \\
\text { be generalized to } \\
\text { traditional SC. } \\
\text { Three abstraction } \\
\text { levels are } \\
\text { proposed: } \\
\text { concept, model } \\
\text { and software }\end{array}$ & $\begin{array}{l}\text { Only mathematical } \\
\text { modelling, but the } \\
\text { authors mention } \\
\text { that some dedicated } \\
\text { formalisms are } \\
\text { under development }\end{array}$ \\
\hline $\begin{array}{l}\text { Labarthe } \\
\text { et al. } \\
\text { (2007) }\end{array}$ & $\begin{array}{l}\text { Only two types } \\
\text { of agent } \\
\text { architectures are } \\
\text { allowed: } \\
\text { cognitive and } \\
\text { reactive. The } \\
\text { methodology } \\
\text { proposes three } \\
\text { modelling steps } \\
\text { with specific } \\
\text { modelling rules }\end{array}$ & $\begin{array}{l}\text { Agents roles and collective } \\
\text { behaviours are explicitly } \\
\text { identified }\end{array}$ & $\begin{array}{l}\text { Design perspective is } \\
\text { top-down, with no } \\
\text { support for reuse }\end{array}$ & $\begin{array}{l}\text { The generality is } \\
\text { between medium } \\
\text { to high, since it } \\
\text { is dedicated to } \\
\text { mass } \\
\text { customization, } \\
\text { but almost all } \\
\text { concepts can be } \\
\text { generalized. } \\
\text { Abstractabily is } \\
\text { definitively } \\
\text { present, with } \\
\text { three major } \\
\text { abstract levels } \\
\text { (conceptual, } \\
\text { operational and } \\
\text { exploitation) }\end{array}$ & $\begin{array}{l}\text { Responsibility } \\
\text { Networks, ABR } \\
\text { (Tranvouez, 2001), } \\
\text { AUML and some own } \\
\text { formalisms }\end{array}$ \\
\hline
\end{tabular}

Table 6. Studied methodological works organized into four groups according to the project

Karam et al. (2010) present an organization oriented methodological framework for modelling and simulation of SC. It allows observations of different levels of details while reproducing the SC behaviour. This methodological framework is structured 
according to a conceptual and an operational abstraction levels. At the conceptual level, the modelling is based on a Conceptual Role Organizational Model (CROM), which is then refined into a Conceptual Agent Organizational Model (CAOM). At the operational level, modelling is mainly based on the Operational Agent Model (OPAM). This framework permits the study of the impact of a specific SC organizational structure and its related management policies on SC performance.

The FAMASS (FORAC Architecture for Modelling Agent-based Simulation for Supply chain planning) framework (Santa-Eulalia et al., 2010; Santa-Eulalia et al., 2008) takes its inspiration from theoretical contributions found in the field of simulation, systems theory, distributed decision making and agent-based software engineering. It proposes a conceptual framework for modelling simulation requirements in d-APS systems. At the conceptual level, FAMASS proposes a schema for defining the simulation problem and translates it into a distributed model. Next, at the agent level, one can convert the distributed model into an agent-based system comprising social and individual aspects. The framework is pretty much dedicated to the analysis phase, but indications on how to transform analysis models into specification and design ones are provided.

The DIMA (Decentralized Integrated Modelling Approach) (Ivanov, 2009; Ivanov et al., 2007a; Ivanov et al., 2007b) introduces a new conceptual architecture for multi-disciplinary modelling of structural planning and operations of adaptive SC with dynamics considerations, employing concepts from control theory, operations research, and agent-based modelling. The main objective is to establish a basis for SC modelling where partial models and algorithms of SC planning and control can be created. In their approach, conceptual business models, mathematical models and software architectures are matched with each other taking into account specific SC features related to dynamics and agility.

Labarthe et al. (2007) propose an approach for modelling customer-centric supply chain in the context of mass customization. They define a conceptual model for supply chain modelling and show how multi-agent systems can be implemented using predefined agent platforms. After creating the Domain Model, the Conceptual Agent Model and the Operational Agent Model, a Multi-Agent System is implemented and a set of experimental plans supports the realization of simulation experiments.

Three of these projects are somehow connected. Taking their inspiration from the agent-based software engineering school, Labarthe et al. (2007) strongly influenced Karam et al. (2010), and it is largely employed in the FAMASS approach for the 
specification and design phases. On the other hand, the DIMA approach follows a different school, more influenced by the system and control theory.

Table 6 helps us understand some issues. First of all, in terms of methodological phases, one can note that the unique work dealing explicitly with the analysis phase is FAMASS, in which a dedicated set of theoretical models combined with specific guidelines and formalisms are proposed to support analysts in mapping function requirements of d-APS systems. The remaining works do not mention the analysis phase. As for the specification and design phases, excluding the FAMASS approach, all works can be used for specification and design. Although they do not state it, the proposed frameworks contain elements to do so. For example, the conceptual and operation models of Karam et al. (2010) and of Labarthe et al. (2007) provide guidelines to define formal (specification phase) and executable (design phase) models. Perhaps the most complete work for specification and design is Labarthe et al. (2007), although it is not formally dedicated to d-APS systems, since no APS functions and modules are explored. In fact, the sole approach entirely covering this issue is the FAMASS framework.

As for the modelling level, it is interesting to note that Karam et al. (2010) do not provide domain models for defining SC planning and control mechanisms. The other three approaches provide one or more artefacts to do so. For example, FAMASS provides a specific set of models for defining the simulation problem as well as the distributed SC planning functions. Also, DIMA proposes some decision-making models for SC planning, control and reconfiguration. Additionally, Labarthe et al. (2007) provide several modelling objects to create an SC system. Despite their significant differences, all four approaches contain elements for defining agent models. The only approach dealing superficially with this issue is DIMA, in which agents are only generally defined.

The descriptive evaluation according to Karageorgos \& Mehandjiev (2004) indicates that the surveyed works have several elements of a complete agent-based methodology, but some elements are still lacking in many works. As identified previously, each approach deals with heuristics support, non-functional aspects, design automation, and each proposes a tool support. In terms of concepts, FAMASS and DIMA do not limit the agent architecture one can use, while the other two favour two classic types (i.e. cognitive and reactive ones). In terms of "design in scope", all of them provide specific modelling steps and rules, although this is not totally clear in DIMA. As for the "models" perspective, agents' roles are clearly identified in all of them. In terms of "process", it can be said that most approaches 
follow basically a top-down approach, even if FAMASS would also allow for a bottom-up logic. This criterion is not completely clear in the DIMA approach. In terms of "pragmatics", although Labarthe et al. (2007) is dedicated to mass customization in SC and DIMA is for dynamic SC (mainly virtual enterprises and collaborative networks), their "generality" can be considered high, as well as their "abstractability".

Finally, apart from DIMA, which employs only mathematical modelling, all of them use specific software engineering formalisms, notably derived from UML.

\section{Discussion and final remarks}

To model complex supply chain planning processes, a set of modelling techniques and approaches exist. In an attempt to organize the literature review in the area, a taxonomical organization was proposed. This indicates that a variety of ways exist to capture SC behaviours, understand, organize, represent d-APS problems and later implement and use d-APS solutions.

Based on this classification, this work focused on the methodological aspects of the agent-based frameworks for d-APS systems, a specific category of the existing modelling and simulation approaches (see subsection 2.2). Two comparative analyses were done: first, a general search covering works dealing with supply chain planning using agent-based approaches was performed; later it was channelled into discussing the approaches explicitly containing methodological aspects for modelling agent-based systems.

\subsection{Main conclusions}

The first comparative analysis indicated that the main contributions of the surveyed works cover several topics, but many propose modelling structures (e.g. modelling frameworks, architectures, approaches and methodologies) without formally defining what these structures are. It is known that these labels can have different meanings and implications, but this is not clearly considered in the concerned literature. In terms of "SC problems" being treated by these manuscripts, a trend to focus on two aspects was noted: "SC relationships" (i.e. coordination, cooperation, information sharing, negotiation and integration) and "production planning and control" (i.e. SC planning, scheduling, control and execution). There is some interesting room for other domains, such as SC governance, sustainability, adaptability, and network design, for instance. In terms of applications, despite the fact that some were found in several domains (such as pharmaceuticals, forest 
products, bicycles, golf clubs, defence), more than half of the works are of a theoretical nature, with few real-scale industrial applications. In terms of technical aspects, it was found that: agent-based "modelling toolkits" are employed in less than $20 \%$ of the identified works; in almost $80 \%$ of them no methodological aspect is formally treated; "APS architectures and engines" are not considered unambiguously in almost all papers; the "social and individual aspects" of the agent society is not taken into account in a clear manner in many of the selected papers. By exploring this first comparative analysis, one can see that many approaches are highly specialized in specific domains and cannot properly capture the complexity of a d-APS system in general terms. One of the most important findings is that most of the literature fails to understand "methodological concerns" and does not provide answers to simple questions, regarding what type of models and simulations can be performed for treating different SC planning problems.

This conclusion led us to an additional comparative analysis that focused on the methodological aspects of some of the works. It was identified that only $21 \%$ address methodological concerns. Among them, only one paper is dedicated to the "analysis phase", and none of them covers the entire developed process in an integrated manner. The most complete work integrating "specification and design" is not formally dedicated to d-APS systems, since no APS functions and modules are explored. Additionally, the sole approach that clearly covers d-APS systems entirely (with specialized entities) does not propose an integrated modelling process from analysis to experimentation. In general terms, it is possible to affirm that different "modelling levels" and "agent models" are identified in the selected works. On the other hand, the descriptive evaluation using the Karageourgous \& Mehandjiev (2004) approach indicates that the surveyed works have many elements of a complete agent-based methodology, but many issues are still lacking, including heuristics support, non-functional aspects, design automation, and tool support proposal. The remaining elements are treated somehow by the papers, with different degrees of detail and completeness.

All these findings indicated that the domain is flourishing and that many interesting theoretical and practical implications and opportunities exist.

\subsection{Theoretical and practical implications and opportunities}

It is important to highlight one of the most fundamental implications of the general scenario in this research field. When talking about supply chain planning systems using some sort of advanced technology (i.e. optimization) and agent-based modelling, the literature still lacks a common representation and understanding of 
the different components and decision processes within the supply chain encapsulated in an integrative methodological guideline. As a consequence, there is no collective understanding (from both an industrial and academic perspective) of the distributed planning problem entailing a semantic unification in the area that provides both the terminology of the domain and the structure of the concepts to be employed.

In this sense, a novel methodological approach for integrated and collaborative modelling would (i) streamline the development process of innovative SC planning tools; (i) enhance the cooperation of different and multidisciplinary models (and disperse research efforts) of the community (including academics and practitioners); (ii) ease the information and knowledge sharing throughout these models; and ultimately it would (iii) allow for a practical integration of different dAPS from different enterprises in a supply chain in order to facilitate the accomplishment of global supply chain planning.

We believe that the present work can contribute to shedding light on this emerging field and pave the way for new and innovative researches towards a complete methodological framework for d-APS systems, thus permitting academics and practitioners to develop and use such systems to improve the SC planning domain.

\subsection{Limitations and future research}

Several limitations of the present work open up interesting opportunities for future research efforts. The first one concerns the search scope, as defined in Section 3, i.e. the period covered, the selected scientific databases, the selected language and the use of only one assessment framework for the descriptive evaluation part. Future research shall extend this search coverage in order to provide a more complete systematic review.

Derived from the main implications and opportunities pointed out in this work, the team is presently working on the development of a novel methodology extending the work of Santa-Eulalia et al. (2010). The main efforts are related to the extension of the methodology from the analysis phase to further steps of the development process, such as specification, design, implementation and simulation. Another research effort behind this new development is the creation of a metamodel comprising the main modelling entities, decision processes, social and individual aspects of d-APS systems. A future version of this framework is to be published shortly. 


\section{Acknowledgments}

The authors wish to thank the NSERC (National Science and Engineering Research Council of Canada), the FORAC Research Consortium (www.forac.ulaval.ca) and the CAFIR (Research and Creation Committee of the TÉLUQ-UQAM) for their financial support, as well as the anonymous referees for their valuable comments and recommendations to improve the quality of the paper.

\section{References}

Amouzegar, M., \& Moshirvaziri, K. (2006). A simulation framework for networked queue models: Analysis of queue bounds in a $G / G / c$ supply chain. Journal of Applied Mathematics and Decision Sciences, 2006, 1-13. http://dx.doi.org/10.1155/JAMDS/2006/87514

Andreev, M., Rzevski, J., Skobelev, P., Shveykin, P., Tsarev, A., \& Tugashev, A. (2007). Adaptive Planning for Supply Chain Networks. Proceedings of the $3^{\text {rd }}$ International Conference on Industrial Applications of Holonic and Multi-Agent Systems, Regensburg, Germany.

Andrews, J., Benisch, M., Sardinha, A., \& Sadeh, N. (2007). What differentiates a winning agent: An information gain based analysis of TAC-SCM. Proceedings of the Trading Agent Design and Analysis Workshop, Vancouver, Canada.

Baumgaertel, H., \& John, U. (2003). Combining agent-based supply net simulation and constraint technology for highly efficient simulation of supply networks using APS systems. Proceedings of the 2003 Winter Simulation Conference, New Orleans, USA.

Beaudoin, D., Lebel, L., \& Frayret, J. (2007). Tactical supply chain planning in the forest products industry through optimization and scenario-based analysis. Canadian Journal of Forest Research, 37, 128-140. http://dx.doi.org/10.1139/x06-223

Becheikh, N. (2005). La revue systématique de littérature : Utilité et méthode pour les sciences de l'administration. Proceedings of the Chaire FCRSS/IRSC sur le transfer de connaissances et I'innovaiton, Québec, Canada.

Benisch, M., Sardinha, A., Andrews, J., Ravichandran, R., \& Sadeh, N. (2009). CMieux: Adaptive strategies for competitive supply chain trading. SIGecom Exch., 6(1), 1-10. http://dx.doi.org/10.1145/1150735.1150737 
Biwer, A.G., Griffith, S., \& Cooney, C. (2005). Uncertainty analysis of penicillin V production using Monte Carlo simulation. Biotechnology and Bioengineering, 90(2), 167-179. http://dx.doi.org/10.1002/bit.20359

Brugali, D., \& Sycara, K. (2000). Towards agent oriented application frameworks. ACM Computing Surveys, 32(1), 21-26. http://dx.doi.org/10.1145/351936.351957

Bussmann, S., Jennings, N., \& Wooldridge, M. (2004). Multi-agent systems for manufacturing control: A design methodology. Berlin: Springer.

Carvalho, R., \& Custodio, L. (2005). A multiagent systems approach for managing supply-chain problems: A learning perspective. Proceedings of the IEEE International Conference on Integration of Knowledge Intensive Multi-agent, Systems, Boston, USA. http://dx.doi.org/10.1109/KIMAS.2005.1427124

Cavalieri, S.C., Cesarotti, V., \& Introna, V. (2003). A multiagent model for coordinated distribution chain planning. Journal of Organizational Computing and Electronic Commerce, 13(3-4), 267-287. http://dx.doi.org/10.1080/10919392.2003.9681164

Chan, H.K., \& Chan, F.T.S. (2010). Comparative study of adaptability and flexibility in distributed manufacturing supply chains. Decision Support Systems, 48(2), 331-341. http://dx.doi.org/10.1016/i.dss.2009.09.001

Chatfield, D.C., Harrison, T.P., \& Hayya, J.C. (2006). SISCO: An object-oriented supply chain simulation system. Decision Support System, 42, 422-434. http://dx.doi.org/10.1016/j.dss.2005.02.002

Chatfield, D.C., Hayya, J.C., \& Harrison. T.P. (2007). A multi-formalism architecture for agent-based, order-centric supply chain simulation. Simulation Modelling Practice and Theory, 15, 153-174. http://dx.doi.org/10.1016/j.simpat.2006.09.018

Chen, Y.M., \& Wei, C.W. (2007). Multi-agent-oriented approach to supply chain planning and scheduling in make-to-order manufacturing. International Journal of Electronic Business, 5(4), 427-454. http://dx.doi.org/10.1504/IJEB.2007.014787

Chen, M., Yang, T., \& Yen C. (2007). Investigating the value of information sharing in multi-echelon supply chains. Quality and Quantity, 41(3), 497-511. http://dx.doi.org/10.1007/s11135-007-9086-2 
Chwif, L., Barretto, M.R.P., \& Saliby, E. (2002). Supply chain analysis: Spreadsheet or simulation?. Proceedings of the 2002 Winter Simulation Conference, San Diego, USA.

Cid-Yanez, F. Frayret, J.M., \& Léger, F. (2009). Evaluation of push and pull strategies in lumber production: An agent-based approach. International Journal of Production Research, 47(22), 6295-6319.

Dam, K., \& Winikoff, M. (2004). Comparing agent-oriented methodologies. AgentOriented Information Systems. In P. Giorgini, B. Henderson-Sellers, \& M. Winikoff (Ed.), Lecture Notes in Computer Science (pp. 78-93). Berlin: Springer-Verlag.

DoD (1998). Department of Defense (DoD), Modeling and Simulation (M\&S) Glossary, DOD 5000.59-M, January 1998.

Dudek, G., \& Stadtler, G. (2005). Negotiation-based collaborative planning between supply chains partners. European Journal of Operational Research, 163(3), 668687. http://dx.doi.org/10.1016/j.ejor.2004.01.014

Egri, P., \& Vancza, J. (2005). Cooperative planning in the supply network - a multiagent organization model. Proceedings of the $4^{\text {th }}$ International Central and Eastern European Conference on Multi-Agent Systems, Budapest, Hungary.

Emerson, D., \& Piramuthu, S. (2004). Agent-based framework for dynamic supply chain configuration. Proceedings of the 37th Hawaii International Conference on System Sciences, Hawaii, USA. http://dx.doi.org/10.1109/HICSS.2004.1265407

Escalas, J. (2004). Imagine yourself in the product. Journal of Advertising, 33(2), $37-48$.

Feng, S.C., Helaakoski, H., Jurrens, K., \& Kipinä, J. (2007). Software agentsenabled systems coalition for integrated manufacturing processes and supply chain management. International Journal of Manufacturing Technology and Management, 11(2), 157-173. http://dx.doi.org/10.1504/IJMTM.2007.013183

Forget, P., D'Amours, S., Frayret, J.M., \& Gaudreault, J. (2008). Study of the performance of multi-behaviour agents for supply chain planning. Computers in Industry, 60(9), 698-708. http://dx.doi.org/10.1016/j.compind.2009.05.005

Fox, M., Barbuceanu, M., \& Teigen, R. (2000). Agent-oriented supply-chain management. International Journal of Flexible Manufacturing Systems, 12(2/3), 165-188. http://dx.doi.org/10.1023/A:1008195614074 
Fox, M., Barbuceanu, M., Gani, M., \& Beck, C. (1993). The integrated supply chain management system. Internal Report - Department of Industrial Engineering, University of Toronto, Canada. http://www.eil.utoronto.ca/iscm-descr.html - Accessed October 2006.

Frayret, J.M., D'Amours, S., Rousseau, A., Harvey, S., \& Gaudreault, J. (2007). Agent-based supply-chain planning in the forest products industry. International Journal of Flexible Manufacturing Systems, 19(4), 358-391. http://dx.doi.org/10.1007/s10696-008-9034-z

Galland, S. (2001). Approche multi-agents pour la conception et la construction d'un environnement de simulation en vue de l'évaluation des performances des ateliers multi-sites, Ph.D. Dissertation, École Nationale Supérieure des Mines et Université Jean Monnet, France.

Galland, S., Grimaud, F., Beaune, P., \& Campagne J. (2003). MAMA-S: An introduction to a methodological approach for the simulation of distributed industrial systems. International Journal of Production Economics, 85, 11-31. http://dx.doi.org/10.1016/S0925-5273(03)00083-5

Ganga, G.M.D. (2010). Proposta de um modelo de simulação baseado em lógica fuzzy e no SCOR para predizer o desempenho da empresa-foco em cadeias de suprimentos, Ph.D. Dissertation, Federal University of Sao Carlos, Brazil.

Gaudreault J., Forget, P., Frayret, J.M., Rousseau, A., \& D'Amours, S. (2009). Distributed operations planning in the lumber supply chain: Models and coordination. CIRRELT Working Paper CIRRELT-2009-07, http://www.cirrelt.ca Accessed December 2009.

Giorgini, P., Kolp, M., Mylopoulos, J., \& Pistore, M. (2003). The Tropos methodology: An overview. In F. Bergenti, M.P. Gleizes, \& F. Zambonelli (Ed.), Methodologies and Software Engineering for Agent Systems. New York: Kluwer Academic Publishing.

Gjerdrum, J., Shah, N., \& Papageorgiou, L.G. (2001). A combined optimization and agent-based approach to supply chain modelling and performance assessment. Production Planning and Control, 12, 81-88. http://dx.doi.org/10.1080/09537280150204013

Govindu, R., \& Chinnam, R. (2010). A software agent-component based framework for multi-agent supply chain modelling and simulation. International Journal of 
Modelling and Simulation, 30(2), 155-171. http://dx.doi.org/10.2316/Journal.205.2010.2.205-4931

Iglesias, C., González, J., \& Velasco, J. (1998). Analysis and design of multiagent systems using MAS-CommonKADS. In M.P. Singh, A. Rao, \& M.J. Wooldridge, Lecture Notes in Computer Science (pp. 313-327). Berlin: Springer Verlag.

Ivanov, D.A., Kaeschel, J., \& Sokolov, B. (2007a). Integrated modelling of agile enterprise networks. International Journal of Agile Systems and Management, 2(1), 23-49.

Ivanov, D.A. (2009). Structure dynamics control-based framework for adaptive reconfiguration of collaborative enterprise networks. International Journal of Manufacturing Technology and Management, 17(1/2), 23-41. http://dx.doi.org/10.1504/IJMTM.2009.023777

Ivanov, D.A., Sokolov, B., \& Kaeschel, J. (2010). A multi-structural framework for adaptive supply chain planning and operations control with structure dynamics considerations. European Journal of Operational Research, 200(2), 409-420. http://dx.doi.org/10.1016/j.ejor.2009.01.002

Ivanov, D.A., Arkhipov, A.V., \& Sokolov, B.V. (2007b). Intelligent planning and control of manufacturing supply chains in virtual enterprises. International Journal of Manufacturing Technology and Management, 11(2), 209-227. http://dx.doi.org/10.1504/IJMTM.2007.013192

Jankowska, A., Kurbel, K., \& Schreber, D. (2007). An architecture for agent-based mobile supply chain event management. International Journal of Mobile Communications, 5(3), 243-258. http://dx.doi.org/10.1504/IJMC.2007.012393

Jarras, I., \& Chaib-draa, B. (2002). Aperçu sur les systèmes multiagents. CIRANO Centre Universitaire de Recherche en Analyse des Organisations. http://www.cirano.qc.ca - Accessed January 2011.

Jung, H., Chen, F.F., \& Jeong, B. (2008). Decentralized supply chain planning framework for third party logistics partnership. Computers \& Industrial Engineering, 55, 348-364. http://dx.doi.org/10.1016/j.cie.2007.12.017

Karageorgos, A., \& Mehandjiev, N. (2004). A design complexity evaluation framework for agent-based system engineering methodologies. In A. Omicini, A. Petta, \& J. Pitt, (Ed.), Lecture Notes in Computer Science: Engineering Societies in the Agents World. Berlin: Springer. 
Karam M., Tranvouez, B., Espinasse, B., \& Ferrarini, A. (2010). An Organizationoriented methodological framework for agent-based supply chain simulation. Proceedings of the $4^{\text {th }}$ International Conference on Research Challenges in Information Science, Nice, France.

Kazemi, Z.M., Aït-Kadi, D., \& Nourelfath, M.(2010). Robust production planning in a manufacturing environment with random yield: A case in sawmill production planning. European Journal of Operational Research, 201(3), 882-891. http://dx.doi.org/10.1016/i.ejor.2009.03.041

Kim, B., \& Oh, H. (2005). The impact of decision-making sharing between supplier and manufacturer on their collaboration performance. Supply Chain Management: An International Journal, 10(3), 223-236. http://dx.doi.org/10.1108/13598540510606287

Kim, H.S., \& Cho, J.H. (2010). Supply chain formation using agent negotiation. Decision Support Systems, 49(1), 77-90. http://dx.doi.org/10.1016/j.dss.2010.01.004

Kitchenham, B., Brereton, O.P., Budgen, D., Turner, M., Bailey, J., \& Stephen, L. (2009). Systematic literature reviews in software engineering - A systematic literature review. Information and Software Technology, 51, 7-15. http://dx.doi.org/10.1016/j.infsof.2008.09.009

Kleijnen, J. (2005). Supply chain simulation tools and techniques: A survey. International Journal of Simulation \& Process Modelling, 1(1/2).

Kwon, O., Im, G., \& Lee, K. (2005). MACE-SCM: An effective supply chain decision making approach based on multi-agent and case-based reasoning. Proceedings of the 38th Annual Hawaii International Conference on System Science, Hawaii, USA. http://dx.doi.org/10.1109/HICSS.2005.396

Labarthe, O., Espinasse, B., Ferrarini, A., \& Montreuil, B. (2007). Toward a methodological framework for agent-based modelling and simulation of supply chain in a mass customization context. Simulation Modelling Practice and Theory, 15(2), 113-136. http://dx.doi.org/10.1016/j.simpat.2006.09.014

Lau, R., Li, Y., Song, D., \& Kwok, R. (2008). Knowledge discovery for adaptive negotiation agents in e-marketplaces. Decision Support Systems, 45(2), 310-323. http://dx.doi.org/10.1016/j.dss.2007.12.018

Lee, C., \& Liu, A. (2002). A method for agent-based system requirements analysis. Proceedings of the IEEE Fourth International Symposium on Multimedia Software Engineering, Newport Beach, USA. 
Lee, H., \& Billington, C. (1993). Material management in decentralized supply chains. Operation Research, 41(5), 835-847. http://dx.doi.org/10.1287/opre.41.5.835

Lee, J., \& Kim, C. (2008). Multi-agent systems applications in manufacturing systems and supply chain management: a review paper. International Journal of Production Research, 46(1), 233-265. http://dx.doi.org/10.1080/00207540701441921

Lee, S., \& Kumara, S. (2007). Decentralized supply chain coordination through auction markets: Dynamic lot-sizing in distribution networks. International Journal of Production Research, 45(20), 4715-4733. http://dx.doi.org/10.1080/002075406008444050

Lemieux, S., D'Amours, S., Gaudreault, J., \& Frayret, J. (2009). Agent-based simulation to anticipate impacts of tactical supply chain decision-making in the lumber industry. International Journal of Flexible Manufacturing Systems, 19(4), 358-391.

Lendermann, P., Gan, B.P., \& McGinnis, L.F. (2001). Distributed simulation with incorporated APS procedures for high-fidelity supply chain optimization. Proceedings of the 2001 Winter Simulation Conference, Arlington, USA.

Lin, F., Kuo, H., \& Lin, S. (2008). The enhancement of solving the distributed constraint satisfaction problem for cooperative supply chains using multi-agent systems. Decision Support Systems, 45(4), 795-810. http://dx.doi.org/10.1016/j.dss.2008.02.001

Lin, F., Tan, G., \& Shaw, M. (1998). Modeling supply-chain networks by a multiagent system. Proceedings of the $31^{\text {st }}$ Annual Hawaii International Conference on System Sciences, Hawaii, USA.

Michel, F., Gouaïch, A., \& Ferber, J. (2003). Weak interaction and strong interaction in agent based simulations. In D. Hales, B. Edmonds, E. Norling, \& J. Rouchier (Ed.), Lecture Notes in Computer Science: Multi-Agent-based Simulation III (pp. 43-56). Berlin: Springer. http://dx.doi.org/10.1007/978-3-540-24613-8 4

Monostori, L., Vancza, J., \& Kumara, S.R.T. (2006). Agent-based systems for manufacturing. CIRP Annals - Manufacturing Technology, 55(2), 697-720.

Monteiro, T., Anciaux, D., Espinasse, B., Ferrarini, A., Labarthe, O., Montreuil, B., \& Roy, D. (2008). L'intérêt des agents pour la simulation de la chaîne logistique, In C. Thierry, A. Thomas, \& G. Bel (Ed.), La simulation pour la gestion des chaînes logistiques. Paris: Lavoisier. 
Monteiro, T., Roy, D., \& Anciaux, D. (2007). Multi-site coordination using a multiagent system. Computers in Industry, 58(4), 367-377. http://dx.doi.org/10.1016/j.compind.2006.07.005

Montreuil, B., Frayret, J.M. \& D'Amours, S. (2000). A strategic framework for networked manufacturing. Computers in Industry, 42(2-3), 299-317. http://dx.doi.org/10.1016/S0166-3615(99)00078-0

Moyaux, T., Chaib-draa, B., \& D'Amours, S. (2007). Information sharing as a coordination mechanism for reducing the bullwhip effect in a supply chain. IEEE Transactions on Systems, Man and Cybernetics Part C: Applications and Reviews, 37(3), 396-409. http://dx.doi.org/10.1109/TSMCC.2006.887014

Ng, W., \& Piplani, R. (2003). Simulation workbench for analysing multi-echelon supply chains. Integrated Manufacturing Systems, 14(5), 449-457. http://dx.doi.org/10.1108/09576060310477852

Nishioka, Y. (2004). Collaborative agents for production planning and scheduling (CAPPS): A challenge to develop a new software system architecture for manufacturing management in Japan. International Journal of Production Research, 42(17), 3355-3368. http://dx.doi.org/10.1080/00207540410001695989

Orcun, S., Asmundsson, R., Uzsoy, R., Clement, J., Pekny, J., \& Rardin, R. (2007). Supply chain optimisation and protocol environment (SCOPE) for rapid prototyping and analysis of complex supply chains. Production Planning and Control, 18, 388-406. http://dx.doi.org/10.1080/09537280701417116

Ouhimmou, M., D'Amours, S., Beauregard, R., Aït-Kadi, D., \& Chauhand, S. (2008). Furniture supply chain tactical planning optimization using a time decomposition approach. European Journal of Operational Research, 189(3), 952-970. http://dx.doi.org/10.1016/j.ejor.2007.01.064

Padgham, L., \& Winikoff, M. (2002). Prometheus: A pragmatic methodology for engineering intelligent agents. Proceedings of the Workshop on Agent-oriented Methodologies at OOPSLA 2002, Seattle, USA.

Pan, A., Leung, S.Y.S, Moon, K.L., \& Yeung, K.W. (2009). Optimal reorder decisionmaking in the agent-based apparel supply chain. Expert Systems with Applications, 36, 8571-8581. http://dx.doi.org/10.1016/j.eswa.2008.10.081 
Paolucci, M., Revetria, R., \& Tonelli, F. (2008). An Agent-based system for sales and operations planning in manufacturing supply chains. WSEAS Transactions on Business and Economics, 3(5), 103-112.

Parunak, H.V.D. (1998). Practical and industrial applications of agent-based systems. Environmental Research Institute of Michigan (ERIM).

Parunak, H.V.D., Baker, A.D., \& Clark, S. (2001). The AARIA agent architecture: From manufacturing requirements to agent-based system design. Integrated Computer-Aided Engineering, 8, 45-58.

Parunak, V., \& VanderBok, R. (1998). Modeling the extended supply network. Industrial Technology Institute.

Penker, M., \& Wytrzens, K. (2005). Scenarios for the Austrian food chain in 2020 and its landscape impacts. Landscape and urban planning, 71(2-4), 175-189. http://dx.doi.org/10.1016/j.landurbplan.2004.03.002

Pfleeger, S., \& Atlee, J. (2006). Software engineering: Theory and practice. New Jersey: Pearson Prentice Hall.

Sadeh, N.M., Hildum, D., Kjenstad, D., \& Tseng, A. (1999). MASCOT: An agentbased architecture for coordinated mixed-initiative supply chain planning and scheduling. Proceedings of the Agents' 99 Workshop Agent-based DecisionSupport for Managing the Interned-Enabled Supply-Chain, Seattle, USA.

Samuelson, D. (2005). Agents of change: how agent-based modeling may transform social science. OR/MS Today, 32(1).

Santa-Eulalia, L.A., Frayret, J.M., \& D'Amours, S. (2008). Essay on conceptual modelling, analysis and illustration of agent-based simulations for distributed supply chain planning. INFOR: Information Systems and Operational Research, 46(2), 97-116. http://dx.doi.org/10.3138/infor.46.2.97

Santa-Eulalia, L.A., D'Amours, S., Frayret, J.M., \& Azevedo, R.C. (2009a). On supply chain modelling and simulation techniques: A literature review taxonomy. Proceedings of the XI SIMPEP Simpósio de Engenharia de Produção, Bauru, Brazil.

Santa-Eulalia, L.A., Aït-Kadi, D., D'Amours, S., Frayret, J.M., \& Lemieux, S. (2009b). Evaluating tactical planning and control policies for a softwood lumber supply chain through agent-based simulations Proceedings of the IESM'2009 
International Conference on Industrial Engineering and System Management, Montréal, Canada.

Santa-Eulalia, L.A. (2009). Agent-based simulations for advanced supply chain planning: A methodological framework for requirements analysis and deployment, Ph.D. Dissertation. Faculté des Sciences et Génie, Université Laval, Canada.

Santa-Eulalia, L.A., D'Amours, S., \& Frayret, J.M. (2010). Modelling agent-based simulations for supply chain planning: the FAMASS methodological framework. Proceedings of the 2010 IEEE International Conference on Systems, Man, and Cybernetics, Special Session on Collaborative Manufacturing and Supply Chains, Istanbul, Turkey.

Santa-Eulalia, L.A., Aït-Kadi, D., D'Amours, S., Frayret, J.M., \& Lemieux, S. (in press). Agent-based experimental investigations about the robustness of tactical planning and control policies in a softwood lumber supply chain. Production Planning \& Control.

Sauter, J.A., Parunak, H.V.D., \& Goic, J. (1999). ANTS in the supply chain. Proceedings of the Agents' 99 Workshop Agent-based Decision-support for Managing the Interned-enabled Supply-chain, Seattle, USA.

Shen, W., \& Norrie, D.H. (1999). Agent-based systems for intelligent manufacturing: A state-of-the-art survey. Knowledge and Information Systems, an International Journal, 1(2), 129-156.

Shen, W., Norrie, D.H., \& Barthès, J.P. (2001). Multi-agent systems for concurrent intelligent design and manufacturing. London: Taylor \& Francis.

Shin, H.J. (2007). Collaborative production planning in a supply-chain network with partial information sharing. International Journal of Advanced Manufacturing Technology, 34, 981-987. http://dx.doi.org/10.1007/s00170-006-0664-6

Si, Y., Edmond, D., Dumas, M., \& Chong, C. (2007). Strategies in supply chain management for the Trading Agent Competition. Electronic Commerce Research and Applications, 6(4), 369-382. http://dx.doi.org/10.1016/j.elerap.2006.12.001

Silva, C.A., Sousa, J.M.C, Runker, T.A., \& Sá da Costa, J.M.G. (2009). Distributed supply chain management using ant colony optimization. European Journal of Operational Research, 199, 349-358. http://dx.doi.org/10.1016/j.ejor.2008.11.021 
Stadtler, H. (2005). Supply chain management and advanced planning - basics, overview and challenges. European Journal of Operational Research, 163, 575588. http://dx.doi.org/10.1016/j.ejor.2004.03.001

Strader, T.J., Lin, F.R., \& Shaw, M.J. (1998). Simulation of order fulfilment in divergent assemble supply chains. Journal of Artificial Societies and Social Simulation, 1(2), <http://jasss.soc.surrey.ac.uk/1/2/5.html>.

Swaminathan, J., Smith, S., \& Sadeh, N. (1998). Modeling supply chain dynamics: A multiagent approach. Decision Sciences, 29(3), 607-632. http://dx.doi.org/10.1111/j.1540-5915.1998.tb01356.x

Tranvouez, E. (2001). IAD et ordonnancement: Une approache coopérative du réordonnancement par systèmes multi-agents. Ph.D. Thesis, Université de Valenciennes et du Hainaut-Cambrésis.

Tranvouez, E., \& Ferrarini, A. (2006). MultiAgent Modelling of Cooperative Disruption Management in Supply Chains. Proceedings of the IEEE International Conference on Service System and Service Management (ICSSSM'06), Troyes, France, October 2006.

Tweedale, J. (2007). Innovations in multi-agent systems. Journal of Network and Computer Applications, 30, 1089-1115. http://dx.doi.org/10.1016/j.jnca.2006.04.005

Ulieru, M., Norrie, D., Kremer, R., \& Shen, W. (2000). A multi-resolution collaborative architecture for web-centric global manufacturing. Information Sciences, 127, 3-21. http://dx.doi.org/10.1016/S0020-0255(00)00026-8

Van Der Vorst, J., Tromp, S., \& Van Der Zee, D.J. (2005). A simulation environment for the redesign of food supply chain networks: Modeling quality controlled logistics. Proceedings of the 2005 Winter Simulation Conference, Orlando, USA. http://dx.doi.org/10.1109/WSC.2005.1574436

Van Der Zee, D.J., \& Van Der Vorst, J. (2005). A Modeling framework for supply chain simulation: Opportunities for improved decision making. Decision Sciences, 36(1), 65-95. http://dx.doi.org/10.1111/j.1540-5915.2005.00066.x

Van Horne, C., \& Marier, P. (2005). The Quebec Wood Supply Game: An on-line tool for knowledge management and transfer. Proceedings of the 59th Forest Products Society Annual Meeting, Québec City, Canada. 
Venkatadri, U., \& Kiralp, R. (2007, May). DSOPP: An intelligent platform for distributed simulation of order promising protocols in supply chain networks. Proceedings of the 8th IFAC International Workshop on Intelligent Manufacturing Systems, Alicante, Spain.

Vernadat, F. (1996). Enterprise modelling and integration: Principles and applications. London: Chapman \& Hall.

Wood, M., \& Deloach, S.A. (2000). An Overview of the multi-agent systems engineering methodology. Proceedings of the $1^{\text {st }}$ International Workshop on Agent-oriented Software Engineering, Limerick, Ireland.

Wooldridge, M., Jennings, N., \& Kinny, D. (2000). The Gaia methodology for agentoriented analysis and design. Autonomous Agents and Multi-Agent Systems, 3, 285-312. http://dx.doi.org/10.1023/A:1010071910869

Wu, J., Cobzaru, M., Ulieru, M., \& Norrie, D. (2000). SC-Web-CS: Supply chain web-centric systems. Proceedings of the IASTED International Conference on Artificial Intelligence and Soft Computing, Banff, Canada.

Yain-Whar, S., Edmond, D., Dumas, M., \& Chong, C.U. (2007). Strategies in supply chain management for the Trading Agent Competition. Electronic Commerce Research and Applications, 6, 369-382. http://dx.doi.org/10.1016/j.elerap.2006.12.001

Journal of Industrial Engineering and Management, 2011 (www.jiem.org)

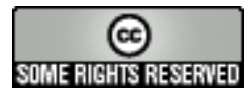

\footnotetext{
Article's contents are provided on a Attribution-Non Commercial 3.0 Creative commons license. Readers are allowed to copy, distribute and communicate article's contents, provided the author's and Journal of Industrial Engineering and Management's names are included. It must not be used for commercial purposes. To see the complete license contents, please visit http://creativecommons.org/licenses/by-nc/3.0/.
} 